\title{
Phylogeographic analysis and species distribution modelling of the wood frog Batrachyla leptopus (Batrachylidae) reveal interglacial diversification in south western Patagonia
}

\author{
José J Nuñez ${ }^{\text {Corresp., } 1}{ }$, Elkin Y Suarez-Villota ${ }^{2}$, Camila A Quercia ${ }^{1}$, Angel P Olivares ${ }^{1}$, Jack W Sites, Jr ${ }^{3,4}$ \\ ${ }^{1}$ Instituto de Ciencias Marinas y Limnológicas, Facultad de Ciencias, Universidad Austral de Chile, Valdivia, Región de Los Ríos, Chile \\ 2 Instituto de Ciencias Naturales, Facultad de Medicina Veterinaria y Agronomía, Universidad de Las Américas, Concepción, Región del Bio-Bío, Chile \\ 3 Department of Biology, Austin Peay St University, Clarksville, Tennessee, United States \\ 4 Department of Biology and M.L. Bean Life Science Museum, Brigham Young University, Provo, Utah, United States \\ Corresponding Author: José J Nuñez \\ Email address: jjnunez@uach.cl
}

Background. The evolutionary history of southern South American organisms has been strongly influenced by Pleistocene climate oscillations. Amphibians are good models to evaluate hypotheses about the influence of these climate cycles on population structure and diversification of the biota, because they are sensitive to environmental changes and have restricted dispersal capabilities. We test hypotheses regarding putative forest refugia and expansion events associated to past climatic changes in the wood frog Batrachyla leptopus distributed along $\sim 1000 \mathrm{~km}$ of length including glaciated and nonglaciated areas in southwestern Patagonia.

Methods. Using three mitochondrial regions (D-loop, cyt $b$, and $c o l$ ) and two nuclear loci (pomc and crybA1), we conducted multilocus phylogeographic analyses and species distribution modelling to gain insights of the evolutionary history of this species. Intraspecific genealogy was explored with maximum likelihood, Bayesian, and phylogenetic network approaches. Diversification time was assessed using molecular clock models in a Bayesian framework, and demographic scenarios were evaluated using approximate Bayesian computation (ABC) and extended Bayesian skyline plot (EBSP). Species distribution models (SDM) were reconstructed using climatic and geographic data.

Results. Population structure and genealogical analyses support the existence of four lineages distributed north to south, with moderate to high phylogenetic support (Bootstrap > 70\%; BPP > 0.92). The diversification time of $B$. leptopus' populations began at $\sim 0.107$ mya. The divergence between $A$ and $B$ lineages would have occurred by the late Pleistocene, approximately 0.068 mya, and divergence between $C$ and $D$ lineages was approximately 0.065 mya. The ABC simulations indicate that lineages coalesced at two different time periods, suggesting the presence of at least two glacial refugia and a postglacial colonization route that gave originated two southern lineages ( $p=0.93$, type I error: $<0.094$, type II error: 0.134). EBSP, mismatch distribution and neutrality indexes suggest sudden population expansion at $\sim 0.02$ mya for all lineages. SDM infers fragmented distributions of $B$. leptopus associated with Pleistocene glaciations. Although the present populations of $B$. leptopus are found in zones affected by the last glacial maximum ( 0.023 mya), our analyses recover an older history of interglacial diversification (0.107 - 0.019 mya). In addition, we hypothesize two glacial refugia and three interglacial colonization routes, one of which gave rise to two expanding lineages in the south. 


\section{Cover Page}

2 Phylogeographic analysis and species distribution modelling of the wood frog

3 Batrachyla leptopus (Batrachylidae) reveal interglacial diversification in south

4 western Patagonia

5

6 José J. Nuñez ${ }^{*}$, Elkin Y. Suárez-Villota ${ }^{2}$, Camila A. Quercia $^{1}$, Angel P. Olivares ${ }^{1}$, and Jack W.

7 Sites $^{3,4}$

9 Full postal addresses:

10 1. Instituto de Ciencias Marinas y Limnólogicas, Facultad de Ciencias, Universidad Austral de

11 Chile, Valdivia, Región de Los Ríos, Chile.

12 2. Instituto de Ciencias Naturales, Facultad de Medicina Veterinaria y Agronomía, Universidad

13 de las Américas, Concepción, Región del Bio-Bío, Chile.

14 3. Department of Biology and Bean Life Science Museum, Brigham Young University, Provo, 15 Utah, 84602 USA.

16 4. Department of Biology, Austin Peay St. Univ., Clarksville, Tennessee, USA.

18 Corresponding Author:

19 José J. Nuñez.

20 Instituto de Ciencias Marinas y Limnólogicas, Facultad de Ciencias

21 Universidad Austral de Chile. Edificio Emilio Pugin,

22 Campus Isla Teja S/N, Valdivia, Chile

23 Email address: jjnunez@uach.cl 
28 Phylogeographic analysis and species distribution modelling of the wood frog Batrachyla 29 leptopus (Batrachylidae) reveal interglacial diversification in south western Patagonia 30

31 José J. Nuñez ${ }^{*}$, Elkin Y. Suárez-Villota ${ }^{2}$, Camila A. Quercia ${ }^{1}$, Angel P. Olivares ${ }^{1}$, and Jack W. 32 Sites $^{3,4}$

34 1. Instituto de Ciencias Marinas y Limnólogicas, Facultad de Ciencias, Universidad Austral de Chile, 35 Valdivia, Región de Los Ríos, Chile.

36 2. Instituto de Ciencias Naturales (ICCNN), Facultad de Medicina Veterinaria y Agronomía, 37 Universidad de las Américas, Concepción, Región del Bio-Bío, Chile.

38 3. Department of Biology and Bean Life Science Museum, Brigham Young University, Provo, 39 Utah, 84602 USA.

40 4. Department of Biology, Austin Peay St. Univ., Clarksville, Tennessee, USA.

42 Corresponding Author:

43 José J. Nuñez.

44 Instituto de Ciencias Marinas y Limnólogicas, Facultad de Ciencias

45 Universidad Austral de Chile. Edificio Emilio Pugin,

46 Campus Isla Teja S/N, Valdivia, Chile

47 email: jinunez@uach.cl

\section{Abstract}

52 Background. The evolutionary history of southern South American organisms has been strongly

53 influenced by Pleistocene climate oscillations. Amphibians are good models to evaluate

54 hypotheses about the influence of these climate cycles on population structure and diversification

55 of the biota, because they are sensitive to environmental changes and have restricted dispersal

56 capabilities. We test hypotheses regarding putative forest refugia and expansion events 
57 associated to past climatic changes in the wood frog Batrachyla leptopus distributed along

$581000 \mathrm{~km}$ of length including glaciated and non-glaciated areas in southwestern Patagonia.

59 Methods. Using three mitochondrial regions ( $D$-loop, cyt b, and $c o l$ ) and two nuclear loci (pomc

60 and $c r y b A 1$ ), we conducted multilocus phylogeographic analyses and species distribution

61 modelling to gain insights of the evolutionary history of this species. Intraspecific genealogy was

62 explored with maximum likelihood, Bayesian, and phylogenetic network approaches.

63 Diversification time was assessed using molecular clock models in a Bayesian framework, and

64 demographic scenarios were evaluated using approximate Bayesian computation (ABC) and

65 extended Bayesian skyline plot (EBSP). Species distribution models (SDM) were reconstructed

66 using climatic and geographic data.

67 Results. Population structure and genealogical analyses support the existence of four lineages

68 distributed north to south, with moderate to high phylogenetic support (Bootstrap $>70 \%$; BPP >

69 0.92). The diversification time of $B$. leptopus' populations began at $\sim 0.107$ mya. The divergence

70 between A and B lineages would have occurred by the late Pleistocene, approximately 0.068

71 mya, and divergence between $\mathrm{C}$ and $\mathrm{D}$ lineages was approximately 0.065 mya. The ABC

72 simulations indicate that lineages coalesced at two different time periods, suggesting the

73 presence of at least two glacial refugia and a postglacial colonization route that gave originated

74 two southern lineages ( $p=0.93$, type I error: $<0.094$, type II error: 0.134). EBSP, mismatch

75 distribution and neutrality indexes suggest sudden population expansion at $\sim 0.02$ mya for all

76 lineages. SDM infers fragmented distributions of B. leptopus associated with Pleistocene

77 glaciations. Although the present populations of B. leptopus are found in zones affected by the

78 last glacial maximum ( $\sim 0.023$ mya), our analyses recover an older history of interglacial 
79 diversification (0.107 - 0.019 mya). In addition, we hypothesize two glacial refugia and three

80 interglacial colonization routes, one of which gave rise to two expanding lineages in the south.

\section{Introduction}

The southern South American landscape is characterised by dynamic transformations

84 resulting from tectonic processes and climatic cycles (Ortíz-Jaureguizar \& Cladera, 2006; Le Roux, 2012). In particular, geological studies (Mercer, 1972; Rabassa \& Clapperton, 1990; Clark et al., 2009) have demonstrated that in the southwestern part of Patagonia have occurred at least four Pleistocene glaciations, including the most extensive Andean glaciation (1.1 mya), the coldest Pleistocene glaciation (0.7 mya), the last southern Patagonian glaciation (180 kya), and the Last Glacial Maximum (LGM; 20,500 and 14,000 years BP). It has been hypothesized that these climatic cycles, re-organized the ecosystems structure, altered species abundance and changed distribution patterns of many Patagonian taxa (Sérsic et al., 2011; Giarla \& Jansa, 2015). It is also recognized that some areas served as climate refugia in a vast inhospitable region, and that those refugia provided habitat to species to persist and from which they expanded when environmental conditions were suitables (Keppel et al., 2012). Phylogeographic studies in vertebrates and plants in this area (Sérsic et al., 2011) have highlighted the importance of such glacial refugia, where species survived through glacial maxima, and which today harbour high levels of genetic diversity and differentiated genetic clusters (Ruzzante et al., 2006; Vidal-Russell, Souto \& Premoli, 2011; Zemlak et al., 2011). Postglacial colonization pathways have been also hypothesized for a range of species (Victoriano et al., 2008; González-Ittig et al., 2010; Gallardo et al., 2013; Vidal et al., 2016) to explain how extant populations are connected and how genetic diversity is spatially distributed. 
Amphibians have attracted considerable attention on Pleistocene refugia hypotheses,

103 largely due to their restricted dispersal capabilities that tend to promote allopatric differentiation

104 (Fitzpatrick et al., 2009; Carnaval et al., 2014). Further, amphibians are highly sensitive to

105 habitat disturbances owing to complex life histories, permeable skin, and exposed eggs (Beebee,

106 1996; Prohl, Ron \& Ryan, 2010).

107 In Southwestern Patagonia, most of the amphibian species are endemic (70\%) and

108 strongly associated with humid Valdivian forest (Formas, 1995). These forests contracted into

109 smaller fragments during the more arid phases of the Pleistocene, leading to the isolation and

110 allopatric diversification of forest-associated taxa (Suárez-Villota et al., 2018). One example is

111 the grey wood frog Batrachyla leptopus Bell 1843. This small amphibian (30-35 mm snout vent

112 length) lays the eggs (diameter of ova 3-4 mm) in clusters of 93-146. Clutches are fertilized at

113 the edges of small pools, amidst vegetation or under fallen logs and rocks on the ground, where

114 embryonic development takes place (Busse, 1971; Úbeda \& Nuñez, 2006). When autumnal rains

115 flood the area (March-June), water stimulates hatching, and larvae metamorphose in 5-7 months

116 (Formas, 1976). Batrachyla leptopus has one of the broadest distributions of any Chilean frog

117 (Cuevas \& Cifuentes, 2010), and is threatened by habitat deterioration in most of its geographic

118 range. Furthermore, most of its current distributional area was intensively glaciated during the

119 LGM but its genetic structure and the impact of the habitat lost are poorly known (Heusser \&

120 Flint, 1977; Paskoff, 1977).

121 Thus, while the humid ecological requirements of B. leptopus might in part explain its

122 low abundance and patchy distributional pattern, Quaternary glaciations likely have generated a

123 phylogeographic history linked to glacial refugia. In fact, previous studies of B. leptopus (Formas

124 \& Brieva, 2000; Vidal et al., 2016) have revealed high levels of population divergence as a result 
125 of past climatic oscillations. For example, based on allozyme data Formas and Brieva (2000)

126 inferred that the lack of correlation between genetic and geographical distances among $B$.

127 leptopus populations could be the result of postglacial recolonization. On the other hand, Vidal et

128 al. (2016) hypothesized that populations of B. leptopus originated from geographically

129 differentiated gene pools, and specifically that post-glacial population expansions came from at 130 least two refugia.

131 One important caveat for studies on refugial hypotheses is that they are often tested by

132 revealing patterns of intraspecific relatedness of present-day biota and placing variation and

133 divergence into a single evolutionary context. These approaches entail an inductivist point of

134 view, that is, the view that researchers should first observe and analyse the present-day pattern

135 and only then might explanations emerge in terms of historical processes (Andersson, 1996;

136 Arroyo-Santos, Olson \& Vergara-Silva, 2014; Segovia \& Armesto, 2015). From an epistemic

137 perspective, these approaches cannot progress beyond being speculative first attempts to

138 understand the evolutionary history of a group, because they tend to generate, rather than test,

139 hypotheses (Crisp, Trewick \& Cook, 2011; Papadopoulou \& Knowles, 2016). Approximate

140 Bayesian computation (ABC) methods (Beaumont, Zhang \& Balding, 2002) have introduced

141 novel model comparison and parameter estimation in population genetic and phylogeographic

142 studies (Csilléry et al., 2010; Sunnåker et al., 2013; Inoue et al., 2014). These methods provide

143 an approximation of the posterior distribution of model probabilities and/or parameter values by

144 simulating data with parameters drawn from specified prior distributions, and retaining values

145 that produce data sets similar to the observed data to test alternative hypotheses (Robinson et al., 146 2014; Freeland, 2020). 
148 species distribution modelling (SDM; Phillips et al., 2017). SDM approaches has been widely

149 applied to assessment of species ranges, and evaluate special and temporal hypothesis about

150 current and past species occurrence (Gavin et al., 2014). Accessibility and easy data

151 requirements of correlative SDMs, coupled with the improved availability of paleoclimate

152 simulations, has the special advantage of permitting prediction of distributional potential across

153 scenarios of environmental change. These models are particularly relevant for understanding the

154 effects that ongoing human-caused global climate change will have on biodiversity (Wiens et al.,

155 2009), including the study of glacial refugia (Gavin et al., 2014).

156 In this work, we use a multilocus phylogeographic approach and species distribution

157 modelling to test two independent hypotheses regarding putative forest refugia and expansion

158 events in B. leptopus. We first test the hypothesis that B. leptopus postglacially colonized the

159 southern area of its current distribution assessing whether temporal and demographic patterns are

160 consistent with such a scenario. If B. leptopus expanded postglacially from the LGM, then

161 populations should exhibit the genetic signature of recent rapid expansion, and the divergence

162 time between populations present in non-glaciated and glaciated areas should be consistent with

163 such postglacial expansion. Second, we test the hypothesis that B. leptopus colonized

164 southwestern Patagonia from a single refuge; if B. leptopus expanded southward from a single

165 refuge, then genetic variation in southernmost populations is expected to be low. Alternatively, if

166 B. leptopus expanded from multiple refugia, then greater genetic diversity would be expected in

167 some populations representing suture zones where genetic admixture may have occurred, and

168 several coalescent points should be detected. 
170 reconstructed its phylogeographic relationships under maximum likelihood and Bayesian

171 inference. Second, we estimated divergence time and temporal changes in population size to

172 determine if these were consistent with late Pleistocene events. Then, we examined the

173 demographic history of this species by simulating alternative Pleistocene glaciation scenarios in

174 an ABC framework. Finally, we combined demographic inferences with species distribution

175 modelling in B. leptopus.

177 Materials \& Methods

\section{Sample collection}

179 Between 2009-2018 we collected 130 individuals and buccal swabs (most samples) from 19

180 localities throughout the distributional range of B. leptopus in south western Patagonia (Table 1;

181 Fig. 1). Each sampling site was geo-referenced with a GPS Garmin GPSmap 76CSx. Eight

182 individuals of B. taeniata were used as outgroup. This study was carried out under supervision

183 and approval of the Bioethics and Biosecurity Committee of the Universidad Austral de Chile

184 (UACh, Resolutions No. 236/2015 and 61/15), and the Servicio Agrícola y Ganadero (SAG,

185 Resolution No. 9244/2015).

186

187 DNA extraction, amplification, and sequence alignment

188 Whole genomic DNA was extracted either from liver tissues or buccal swabs according to

189 Broquet et al. (2007), using the manufacturer's recommended protocol for the Qiagen DNeasy

190 tissue kit (Cat. No. 69506). We amplified three mitochondrial regions: a segment of the Control

191 region (D-loop; Goebel, Donnelly \& Atz, 1999) Cytochrome b (cyt b; Degnan \& Moritz, 1992), 
192 and Cytochrome oxidase subunit I (coI; Folmer et al., 1994), and two nuclear regions:

193 Propiomelanocortin (pomc; Gamble et al., 2008) and $\beta$ Crystallin A1 (crybA1; Dolman \&

194 Phillips, 2004), via polymerase chain reaction (PCR). Reaction cocktails for PCR were according

195 to Suarez-Villota et al. (2018). PCR products were sequenced in Macrogen Inc. (Seoul, Korea)

196 and at the DNA Sequencing Center at Brigham Young University (Provo, USA). To transform

197 sequence data to haplotypes we used PHASE v2.1.1 (Stephens \& Donnelly, 2003) with the

198 default model for recombination rate variation (Li \& Stephens, 2003). We aligned sequences

199 using the automatic assembly function in Sequencher v. 4.8 (Gene Codes Corp.), and inspected

200 the aligned sequences by eye, and made corrections manually.

201

202 Molecular diversity and lineage structure

203 Haplotype and nucleotide diversity indexes (Nei, 1987) and their standard deviations, were

204 estimated with DNASP v5.0 (Librado \& Rozas, 2009) using all markers. The possibility of

205 saturation in the rate of base substitutions was assessed by the method of Xia et al. (2003) using

206 DAMBE v6.0 (Xia \& Xie, 2001). Population genetic structure was examined using the package

207 GENELAND v4 implemented in R v3.1.2 (Guillot, Mortier \& Estoup, 2005), to infer the number

208 of populations by giving a spatial model of cluster membership without prior designations.

209 GENELAND was run with a model of uncorrelated allele frequencies for the mitochondrial

210 locus (with all gene regions concatenated). We performed eight independent runs of $1.5 \times 10^{7}$

211 iterations, with thinning set to 500 and a "burn in" of $20 \%$. The number of possible clusters

212 tested ranged from 1 to 19 (according to sampling locations). The level of population structure

213 among the clusters obtained by GENELAND, was assessed by analysis of molecular variance

214 (AMOVA; Holsinger \& Weir, 2009) using ARLEQUIN v3.1 (Excoffier, Laval \& Schneider, 
215 2005) for mtDNA and nDNA separately. Also, using all loci we evaluated whether the sequences

216 evolved under strict neutrality using Tajima’s D (Tajima, 1989), Fu \& Li's D (Fu \& Li, 1993),

217 and $\mathrm{r}^{2}$ (Ramos-Onsins \& Rozas, 2002) tests.

218

219 Phylogenetic trees reconstruction, split networks and divergence time estimates

220 Previous to phylogenetic analyses, evolutionary models and partitioning strategies were

221 evaluated using Bayesian information criterion (BIC) scores (Schwarz, 1978) in

222 PARTITIONFINDER v2.1.1 (Lanfear et al., 2017) (Table S1). The phylogenetic analyses were

223 performed with mitochondrial and nuclear concatenated matrix. Partitioned maximum likelihood

224 analyses were conducted using GARLI 2.0 (Zwickl, 2006) with 200 replicates of nonparametric

225 bootstrap for branch support. Bayesian analyses were performed using MRBAYES v3.2

226 (Ronquist et al., 2012). We performed four independent MCMC runs 50 million generations,

227 sampling every 2,000 generations. Posterior distributions for parameter estimates and likelihood

228 scores to approximate convergence were visualized with the TRACER program v1.6.0 (Rambaut

229 et al., 2014). The effective sample sizes (ESS) of each parameter (>200), allowed us to confirm

230 that the analysis was adequately sampled. A maximum clade credibility tree was visualized with

231 the program FIGTREE v1.4.4 (http://tree.bio.ed.ac.uk/software/figtree/).

232 Posterior probability values $>0.95$ were taken as high statistical support for a clade being present

233 on the true tree (Huelsenbeck \& Rannala, 2004). In order to obtain additional statistical support

234 for the best tree obtained, topologies of different trees (ML and Bayesian) were compared with

235 the use of the Shimodaira-Hasegawa (S-H) test (Shimodaira \& Hasegawa, 1999) with

236 resampling-estimated log likelihood (RELL) and bootstrapping of 1,000 replicates, using the

237 program PAUP*.

PeerJ reviewing PDF | (2020:03:46371:1:1:NEW 9 Jul 2020) 
238 We are aware that phylogenetic methods may not apply at the within-species level, due to

239 multifurcating population genealogies in which descendant alleles coexist with ancestral ones,

240 and recombination events may produce reticulate relationships (Posada \& Crandall, 2001). To

241 consider these caveats, we constructed unrooted phylogenetic networks using the method

242 described by Huson and Bryant (2006), implemented in SPLITSTREE v4.14.4.

243 To determine when major clades and lineages diverged relative to Quaternary glaciation history,

244 we estimated time since the most recent common ancestor (TMRCA), using the reconstructed

245 species tree from concatenated mitochondrial and nuclear sequences. For this reconstruction, we

246 used multi-species coalescent module implemented in *BEAST of BEAST v1.8.4 (Drummond \&

247 Rambaut, 2007; Heled \& Drummond, 2010), and the same models used for phylogenetic tree

248 reconstruction found by PARTITIONFINDER. Due that it is not possible to date any of the

249 nodes within B. leptopus, as there are no fossils or dated biogeographic events, we used as prior

250 Neobatrachian mutation rates of $0.291037 \%$ per million years for COI, rate of $0.37917 \%$ per

251 million years for each other mitochondrial markers (dloop and $c y t b$ ), and a rate of $0.3741 \%$ per

252 million years for pomc sequences, according to Irrisarri et al. (2012). Bayes factor analysis (Li

253 \& Drummond, 2012) indicated that species tree with strict-clock model received decisive nodal

254 support compared to uncorrelated exponential or uncorrelated lognormal relaxed-clock models.

255 Markov chains in BEAST were initialized using the tree obtained by MRBAYES, to calculate

256 posterior parameter distributions, including the tree topology and divergence times. We used

257 BEAST to estimate divergence time, based runs for $2 \times 10^{7}$ generations, and sampling every

258 1000th generation. The first 10\% of samples were discarded as "burn in", and we estimated

259 convergence to the stationary distribution and acceptable mixing (ESS $>200)$ using TRACER

260 v1.6.0. 
262 Population-size dynamics through time

263 Hypotheses of historical demographic expansions and dynamics through geological time of the

264 inferred lineages were estimated by "mismatch distributions" (Rogers \& Harpending, 1992), and

265 Extended Bayesian Skyline Plots (EBSP; Heled \& Drummond, 2008) respectively. We used in a

266 complementary way both approaches due that small sample sizes apparently to fail to provide

267 enough power to Bayesian skyline plots to detect population expansion (Grant, 2015). The

268 smooth, unimodal distributions typical of expanding populations can be readily distinguished

269 from the ragged, multimodal distribution "signatures" of long-term stationary populations, by

270 means of the 'raggedness' of these distributions (Rogers \& Harpending, 1992). Confidence

271 intervals for these estimates were obtained by simulations using the coalescence algorithm as

272 implemented in DNASP v5.0. To estimate population-size dynamics through geological time, we

273 reconstructed Extended Bayesian Skyline Plots (EBSP; Heled \& Drummond, 2008) implemented

274 in BEAST for the four lineages obtained with GENELAND. This coalescent-based,

275 nonparametric Bayesian MCMC algorithm incorporates multi-locus data to reduce error

276 estimates associated with single genes (e.g., traditional Bayesian Skyline Plots), and increases

277 the power to resolve alternative demographic histories (Ho \& Shapiro, 2011). For each EBSP,

278 the appropriate model of nucleotide substitution was determined using PARTITIONFINDER.

279 Genealogies and model parameters for each lineage were sampled every 1000th iteration for

$2802 \times 10^{7}$ generations under a strict molecular clock with uniformly distributed priors and a "burn

281 in" of 2000. Demographic patterns for each analysis were plotted in EXCEL v14.7.7.

282

283 Test of phylogeographical hypotheses with ABC

PeerJ reviewing PDF | (2020:03:46371:1:1:NEW 9 Jul 2020) 
284 A coalescent method was used to test phylogeographic hypotheses by constraining the

285 genealogies to fit alternative evolutionary models, and assessing each model's fit by comparing

286 the observed genetic pattern with the range of simulated patterns. Competing phylogeographic

287 hypotheses were compared using approximate Bayesian computation method (ABC approach),

288 as implemented in DIYABC v2.1 (Cornuet et al., 2014). We evaluated five demographic

289 scenarios to test alternative divergence times and tree topologies of the four main lineages

290 recovered in GENELAND and in the phylogenetic analyses. Furthermore, the divergence of the

291 main four lineages toke place before the last glacial maximum so the divergence scenarios were

292 proved in such range. The refugia hypotheses correspond to the points of coalescence, with four

293 lineages strongly supported, the possibilities of coalescence are from 1 to 3, for which we tested

294 all the possibilities except scenarios with postglacial admixture because there are not paraphyly

295 events between lineages. The prior coalescence points at time times $\mathrm{t} 1$ and $\mathrm{t} 2$ applied in the ABC

296 correspond those estimated by BEAST for the origin of Batrachyla leptopus $(\mathrm{t} 2)$ and the

297 divergence of the four lineages (t1, lower and higher range of the four lineages). Thus, all

298 historically relevant scenarios differed only in the order of population divergence, and in the

299 number and timing of demographic expansion events. These alternatives were: Scenario $1-$ the

300 null model - all four lineages coalesced at $\mathrm{t} 1$ with equal divergence rates. Scenario 2 - also a null

301 model, but all four lineages coalesced at $\mathrm{t} 2$ with equal divergence rates. Scenario 3 - the first

302 coalescence of lineages $\mathrm{A}$ and $\mathrm{B}$ at $\mathrm{t} 1$, whose ancestor coalesced at $\mathrm{t} 2$ with lineage $\mathrm{C}$ and $\mathrm{D}$.

303 Scenario 4 - the first coalescence of lineages $C$ and $D$ at $t 1$, whose ancestor coalesced at $t 2$ with

304 lineage A and B. Scenario 5 - one split event at $t 1$ isolated the north (lineages A and B) from the

305 south (lineages $\mathrm{C}$ and D) clades, and then a coalescence of both clades at t2 (see Results). We 
306 tested other scenarios whose divergence time were lower and the probability was very low so

307 they were not considered.

308 Prior values of $\mathrm{Ne}$ were set as 1,000-500,000 individuals with a uniform distribution, based on

309 Ne calculated from MIGRATE-N v3.6 (Beerli, 2006). For this analysis, we performed maximum

310 likelihood using 10 short chains of 1000 steps, and two long chains of 10000 steps, sampling

311 each 100 steps, and a burn-in of 10 per cent. Ne was calculated using mitochondrial and nuclear

312 rates reported by Irisarri et al. (2012).

313 Prior values for divergence of the ancestral populations were based on divergence times

314 calculated here (see Results), and a generation time of 2-3 yr (Martin \& Palumbi, 1993), using a

315 uniform distribution. Divergence times were set at between 20,000 - 500,000 generations ago for

$316 \mathrm{t} 2$, and 10,000 - 200,000 generations for $\mathrm{t} 1$.

317

318 Paleo-distribution and species distribution modelling

319 A total of 120 occurrence records were used for the species distribution models (SDMs) and

320 paleo-distribution modelling. Records were obtained from peer-reviewed literature, our sampled

321 sites, and online databases (GBIF: gbif.org, VetNet: vertnet.org, and iDigBio: idigbio.org). We

322 modeled the SDMs using the standard 19 bioclimatic variables downloaded from Worldclim

323 (Hijmans et al., 2005) for the current conditions (1960-1990), the Mid Holocene (Mid-Hol,

$324 \sim 6,000$ yrs BP), the LGM ( 22,000 yrs BP), and the Last Inter-glacial (LIG, $120,000-140,000$

325 yrs BP). The variables were at 30 arc-sec for the current conditions and the LIG, and at 2.5 arc-

326 min for the Mid-Hol and LGM. The Mid-Hol and the LGM variables were based on the

327 Community Climate System Model (CCSM) and the Model for Interdisciplinary Research on

328 Climate (MIROC), while LIG conditions were based on Otto-Bliesner et al. (2016). We 
329 restricted the projection of the models by creating a buffer of $2^{\circ}$ around the outermost occurrence

330 records and the known distribution of B. leptopus. All SDMs were performed using MAXENT

331 v3.4.0 (Phillips et al., 2017). To avoid model overfitting and account for the correlation between

332 the variables and the presence of outliers encountered during data exploration, we reduced the

333 number of variables to five. This was performed by retaining the variables with $\mid$ rho $\mid<0.8$ that

334 contributed the most to ten cross-validated models, as shown by a Jackknife test. These variables

335 were Bio2 $=$ Mean Diurnal Range, Bio4 $=$ Temperature Seasonality, Bio5 = Max Temperature of

336 Warmest Month, Bio13 $=$ Precipitation of Wettest Month, and Bio17 $=$ Precipitation of Driest

337 Quarter.

338 For all models, the equal training and sensitivity threshold rule was applied and the cloglog

339 output was selected. Extrapolation was not used and clamping was applied when hind-casting the

340 model of the current conditions to the past. The models for the Mid-Hol and for the LGM were

341 overlaid within each time period to identify areas of agreement and disagreement between the

342 models for each the time period. All models were transformed to binary using the selected

343 threshold rule (Phillips et al., 2017).

\section{Results}

346 Genetic structure using Bayesian clustering model

347 A total of 113 haplotypes were found when mitochondrial and nuclear markers were combined

348 (Table 2). Saturation tests as a function of the genetic distance estimated under substitution

349 model GTR showed non- significative saturation of DNA sequence alignments. The mtDNA

350 Bayesian analysis with GENELAND yielded a modal number of four clusters $(K=4)$, recovered

351 from all independents runs (Fig. 2A); this is based on the highest average posterior probability. 
352 The distribution of these four clusters, from north to south, was named as follows (Fig. 2B):

353 lineage A (Los Queules), lineage B (Nahuelbuta), lineage C (Bahía Mansa, Cordillera Pelada,

354 Máfil, and Pichirropulli), and lineage D (all remaining localities shown in Table 1). The highest

355 estimate of haplotype diversity was found in lineage A, whereas the lowest values were found in

356 lineage B (Table 2). Highest nucleotide diversity was detected in lineage D and the lowest one in

357 lineage B (Table 2). Negative but non-significant values for Tajima's D and Fu's FS neutrality

358 test indexes were found in all lineages except for B lineage. Here the non-significant positive

359 values likely reflected the smallest sample size for this locality. Rozas's $\mathrm{r}^{2}$ were positive for all

360 lineages but only significant for A and B lineages, suggesting recent expansion (Table 2).

361 The AMOVA results using the four lineages indicate a significant genetic structure (groups

362 defined as Lineages A, B, C and D): (1) variation among lineages $=35.64 \%$ and variation within

363 lineages $=45.93 \%$ for $\operatorname{mtDNA}$; (2) variation among lineages $=0 \%$ and variation within lineages

$364=51.12 \%$ for pomc; $(3)$ variation among lineages $=4.49 \%$ and variation within lineages $=$

$3652.74 \%$ for crybAl (Table 3).

366

367 Phylogenetic tree reconstruction, split networks, and lineage divergence time

368 The models selected for the ML and Bayesian analyses are described in Table S1. Because the

369 Bayesian analyses recovered a maximum clade credibility tree similar to the best ML tree, and

370 the Shimodaira-Hasegawa test showed that topological disagreements were restricted to "low-

371 support" nodes, we show only the Bayesian tree (Fig. 3A). The same four lineages recovered by

372 GENELAND were recovered in the phylogenetic reconstruction with moderate to high support

373 values. Lineages A and B were recovered as sister groups (bootstrap $=96 \%$; $\mathrm{BPP}=0.99$ ), as

374 were the $\mathrm{C}$ and $\mathrm{D}$ lineages, but with moderate support (bootstrap 74\%; $\mathrm{BPP}=0.95$ ). 
375 Mitochondrial phylogenetic analyses recovered similar results to concatenated datasets, but the

376 nuclear phylogeny was highly polytomized (Fig. S1). The split networks (Fig. 3B) recovered the

377 same four lineages obtained by the ML and Bayesian analyses. The fit index was 94.96, meaning

378 that only $5.04 \%$ of the distances in the distance matrix are not represented by the network. Most

379 of the internal splits have bootstrap support between 68 and $100 \%$.

380 Divergence dating indicates that the A-B and C-D clades separated during the late Pleistocene, 381 approximately 0.107 mya $[95 \%$ confidence interval $(\mathrm{CI})=0.020-0.278$ mya $]$. The divergence

382 between A and B lineages would have occurred by the late Pleistocene (approximately 0.068

383 mya; 95\% CI $=0.036-0.147$ mya) and divergence between $\mathrm{C}$ and D lineages was approximately

3840.065 mya $(95 \% \mathrm{CI}=0.056-0.092$ mya $)($ Fig. 3A).

385

386 Demographic patterns of the inferred clusters

387 Results of mismatch distribution analyses (Fig. 4A-D) revealed a single primary peak for lineage 388 A, but with a non-significant raggedness index $(r=0.0230, \mathrm{P}>0.1)$. Similarly, unimodal patterns 389 were observed in lineages $\mathrm{C}(\mathrm{r}=0.003, \mathrm{P}<0.001)$ and $\mathrm{D}(\mathrm{r}=0.0008, \mathrm{P}<0.001)$. The small sample

390 size $(\mathrm{n}=7)$ and haplotype numbers $(\mathrm{H}=2)$ precluded this analysis on lineage $\mathrm{B}$. Reconstruction

391 of the demographic histories by means of Extended Bayesian Skyline Plot (Fig. 4E-H )

392 suggested population expansions for all lineages except B (Fig. 4F). EBSP further resolved 393 sequential demographic expansions from the oldest, lineage D (c. 18,000 years bp), then lineage

394 A (c. 11,000 years bp), and most recently, lineage C (c. 5,000 years bp). 395

396 Hypothesis testing with ABC 
397 Logistic regression analysis with DIYABC identified Scenario 4 as most strongly supported

398 among the five tested (Fig. 5D), with a high posterior probability (0.93; Table 4); all other

399 scenarios had much lower support (0.0-0.04). Moreover, the Type I and Type II error rates

400 estimated for Scenario 4 were the lowest in both cases $(0.14 ; 0.014-0.196$; Table 4$)$.

401 Scenario 4 placed the first divergence as the split between lineages A, B, and the ancestor of the

402 southern clade (lineages $\mathrm{C}$ and $\mathrm{D}$ ) at $\mathrm{t} 2$, and the second split between lineages $\mathrm{C}$ and $\mathrm{D}$ at $\mathrm{t} 1$ (Fig.

403 5D). The effective population size ( $\mathrm{Ne}$ ) and divergence time parameters, in terms of the number

404 of generations ( $\mathrm{t}$ ), estimated for this divergence scenario (Table S2), corroborate the population

405 expansions inferred by EBSP and mismatch distribution for lineages C and D.

406

407 SDMs and paleo-distribution models

408 The predicted distribution models of B. leptopus under four periods (last inter-glacial to current)

409 are shown in Fig. 6. The model for the current conditions showed that the distribution of this

410 species is mostly encompassed by the county-based current distribution mapped by the IUCN,

411 with a high AUC value (0.961, $\mathrm{SD}=0.013)$ (Fig. 6A). The two circulation models for the Mid-

412 Hol showed different distributions: the MIROC-based model showed a continuous distribution

413 similar to the current conditions model, while the CCSM-based model resolved disjunct

414 distributions for the northern region of the current distribution model (Fig. 6B). Both LGM

415 models showed clear disjunct distributions with concordance around Nahuelbuta mountain range

416 (Fig. 6C). The MIROC based model indicated a distribution to the north of the current

417 distribution model, and the CCSM resolved a highly fragmented distribution. The model for the

418 LIG showed a disjunct distribution for the species at the northern portion of the current

419 distribution of B. leptopus (Fig. 6D). 


\section{Discussion}

422 Our hindcasting-based approach supports the existence of four lineages in B. leptopus (A, B, C

423 and D; Figs. 2, 3) distributed discontinuously along the narrow, $\sim 1000 \mathrm{~km}$ long Patagonian

424 region of southern Chile. AMOVA confirmed the strongly different patterns of variation among

425 the Batrachyla leptopus populations. In our study, most of the mtDNA genetic differences are

426 present among localities and within lineages (Table 3), with less differentiation among lineages.

427 This indicates the presence of high local genetic structure and high interpopulation

428 differentiation. These results might suggest that although B. leptopus has a wide range of

429 distribution, long-range dispersal is highly unlikely, which is in agreement with historical data.

430 On the other hand, most of the variation in nuclear markers were observed within localities,

431 while the values of both genes were not significant (Table 3).

432 The basic topology of the concatenated ML and Bayesian trees were similar, consequently we

433 used the Bayesian tree as our primary hypothesis of relationships among B. leptopus populations

434 (Fig. 3A). We recovered two main clades (named south and north) and four lineages (A, B, C,

435 and D) strongly supported by boostrap, and posterior probabilities. The nuclear phylogeny was

436 highly polytomized (Fig. S1A, B) and it did not inform on lineages relationships. In contrast, the

437 mtDNA phylogeny (Fig. S1C) was highly informative, separating the same clades of the

438 concatenated data set. Consequently, mtDNA variation was a leading indicator of population

439 differentiation and phylogenetic relationships relative to nuclear loci in B. leptopus, indicating

440 that mitochondrial markers can be more sensitive in revelate lineage divergence than any single

441 nuclear gene, problably because a lower effective population sizes than nuclear genes (Hung,

442 Drovetski \& Zink, 2016). 
444 Biogeographic structure of the lineages

445 The two northernmost lineages (A and B) are currently separated by two major river systems 446 (Itata and Bío Bío; Fig. 1); these boundaries also coincide with a region with sparsely distributed 447 forest patches. These two lineages are genetically well-differentiated from each other (Fig. 2b); 448 lineage A is restricted to the Los Queules Reserve, and lineage B are limited to a small area in 449 Nahuelbuta range (Locality 2) near to the Butamalal River. The evolution of distinct lineages or 450 genetic clusters is often attributed to population isolation during glacial advances, which 451 geographical isolation in combination with different selection pressures and/or genetic drift 452 would drive population divergence (Hewitt, 2004). Similarly, low levels of current genetic 453 diversity as observed in lineage B (Nahuelbuta; Table 2), suggest a recolonization history of 454 founder effects, small population size, and genetic bottlenecks (Hewitt, 2004).

455 In contrast to these well-differentiated/low variability lineages, those in the southern distribution 456 (lineages C and D) are geographically more heterogeneous. Lineage C is widely distributed from 457 Máfil in the Los Ríos region (Locality 3 in Fig. 1) to Bahía Mansa, Los Lagos region (Locality 6 458 in Fig. 1), suggesting that certain landscape features, such as extensive forests, would have 459 allowed dispersal among breeding groups over long timescales. Moreover, the encompassed 460 areas of lineage $\mathrm{C}$ also include large mountains (e.g. Bahía Mansa and Cordillera Pelada; Fig. 1), 461 suggesting that such orography could represent barriers to gene flow in B. leptopus, as reported 462 in some co-distributed vertebrates and plants (Sérsic et al., 2011). The combined dataset suggests

463 that lineage D is widespread throughout the rest of the species' range, with few

464 phylogeographical subdivisions.

465

\section{Lineage divergence time}


467 Divergence time estimates suggest that diversification of B. leptopus lineages may have occurred

468 earlier than reported in other frogs such as the ground frog Eupsophus calcaratus (Nuñez et al.,

469 2011), although co-distributed populations (e.g. Bahía Mansa) appear to have diverged later in

470 time (0.025 mya for B. leptopus (Fig. 3A), and 0.065 mya for E. calcaratus (Nuñez et al., 2011;

471 Fig. 2). Vidal et al. (2016) point out that some B. leptopus populations from Chiloé Island and

472 the mainland (included in Lineage D in our study) diverged approximately 1.1 mya. Our results

473 indicated that the initial split of B. leptopus into the North and South clades was during the Late

474 Pleistocene ( 0.107 mya; Fig. 3). Moreover, the overall pattern suggests that B. leptopus has

475 undergone several rounds of fragmentation, followed by successive radiations within each clade.

476 Further, at least two more recent series of fragmentation events are inferred within each of these

477 clades. Our calibrations place the split between lineages A and B at $\sim 0.068$ mya, and between

478 lineages $\mathrm{C}$ and $\mathrm{D}$ at $\sim 0.065$ mya.

479 The discrepancy in divergence times between our results and those of the Vidal et al. (2016) may

480 be due to the use of different mutations rates $(0.8 \%)$ and a single marker (mitochondrial $c y t b)$. It

481 is well known from population genetics theory that the stochastic nature of the genealogical

482 process implies a significant amount of variance associated with parameter estimation. In fact,

483 Nabholz et al. (2009) suggest that for inferring divergence dates should imperatively use

484 statistical phylogenetic methods accounting for substitution rate variation across lineages.

485 Endeed, analysis of mtDNA sequence data can be enhanced if they are collected in conjunction

486 with nuclear sequences, because they provide an independent estimate of phylogenetic

487 relationships, mitigating the inherent random effects of the randomness inherent to genetic drift,

488 and the significant amount of variance associated with parameter estimation (Carstens \& Dewey,

489 2010). Interpretations derived of the divergence time analyses also need to take into account the 
490 largely overlapping confidence intervals of the results for each lineage divergence. For example,

491 if only the median values are considered, the results suggest coalescence of the lineages C and D

492 at $\mathrm{t} 1$ (around 0.066 mya), and coalescence of the lineages A and B at t2 (around 0.107 mya). But

493 if we consider the confidence intervals, the divergence of both clades, North and South could be 494 closer in time than what is hypothesized in such reconstruction.

495

496 Hypothesized refugia and post-glacial expansion

497 Studies on past contraction-expansion climate cycles in Patagonian landscapes suggest that a

498 rapid population expansion should occur in the biota affected by these processes, as habitats

499 became more available (Fraser et al., 2012). Despite the geomorphological differences in

500 Patagonian landscapes, population genetics theory points out that a population undergoing rapid

501 expansion can be characterized by low genetic diversity, since each new founder population

502 represents only a fraction of the ancestral population (Nichols \& Hewitt, 1994; Hewitt, 2000;

503 Hewitt, 2004; Waters, Fraser \& Hewitt, 2013).

504 The last two Pleistocene glaciations in southwestern South America (180 kya and 20 kya)

505 covered the Andes with large ice fields reaching the Pacific Ocean south to $39^{\circ} \mathrm{S}$, where the ice

506 sheet decreased in elevation to sea level, and extending further to the southern tip of South

507 America (Rabassa, 2011). Consequently, Late-Pleistocene divergence time estimates (0.107

508 mya) for first diversification of B. leptopus populations separating the North and South clades

509 (Fig. 3), are consistent with a hypothesis of Pleistocene isolation followed by interglacial

510 dispersal. In fact, the divergence of lineages A and B suggests that this interglacial dispersal

511 from the ancestral population occurred rapidly across the current range of the species. 
512 The existence of two suitable areas for the species is supported by the SDM for the LIG $(0.120-$

5130.140 mya) in that Los Queules population (Locality 1, Table 1) showed the highest genetic

514 diversity (Table 2). This is typical for refugial populations that have been stable over time

515 (Fraser et al., 2012). This evidence and the agreement of the two circulation models for Los

516 Queules area as a suitable habitat for the species during the LGM (Fig. 6C), suggest that it is

517 highly probable that now Los Queules location is a remnant of the northern refuge, derived from

518 the last southern Patagonian glaciation (180 kya).

519 Demographic reconstruction in B. leptopus using an ABC framework also supports the

520 hypothesis of two putative refugia at different time during the Pleistocene (Scenario 4, Fig. 5D,

521 Table 4). This scenario suggests that the South clade populations (lineages C and D) are likely

522 descended from a divergence event approximately $65 \mathrm{Kya}$. This scenario is concordant with the

523 predicted patchy distribution of the species during the Mid-Holocene ( $\sim 6,000$ years BP; Fig. $6 \mathrm{~B})$.

524 On the other hand, the various demographic analyses show that the genetic structure of lineages

$525 \mathrm{C}$ and D contains signatures of demographic expansion consistent with Pleistocene glacial

526 retreat. In fact, strong support for recent population expansion is represented by significantly

527 negative Fu's Fs values, unimodal mismatch distributions with low raggedness indexes, and

528 EBSP's depicting rapid expansion following the retreat of the Patagonian ice sheet after 15 Kya

529 (Table 2; Fig. 4). This hypothesis is also reinforced with SDMs produced by both circulation

530 models, although when viewed separately, the MIROC circulation model is the only one

531 predicting this scenario.

532

533 Past population dynamics and current conservation significance 
534 During the Cenozoic climatic oscilations included multiple glaciations in southern South

535 America (Rabassa \& Clapperton, 1990; Coronato, Martínez \& Rabassa, 2004). These geological

536 events have been hypothesized as causes of the retreat and advance of temperate Nothofagus

537 forests and conifers (Villagrán \& Hinojosa, 1997; Premoli, Kitzberger \& Veblen, 2000;

538 Tremetsberger et al., 2009). Accordingly, several phylogeographic hypotheses suggest that

539 Pleistocene glaciations had profound effects on the population genetic structure and variability of

540 Patagonian fauna. For example, glaciated populations of some fish species display molecular

541 diversity (high haplotype diversity and low nucleotide diversity) significantly correlated with

542 latitude (Ruzzante et al., 2008; Cosacov et al., 2010). The same genetic patterns have been

543 observed in reptiles (Breitman et al., 2011; Fontanella et al., 2012), amphibians (Nuñez et al.,

544 2011), and mammals (Himes, Gallardo \& Kenagy, 2008; Lessa, D'Elía \& Pardiñas, 2010).

545 In agreement with these previous studies, the location of glacial refugia and postglacial

546 expansion identified here, indicate that the climatic niche of B. leptopus is likely to be related to

547 an increase in the availability of suitable habitat in the southern part of its current distribution.

548 Reconstruction of the potential distribution area of B. leptopus (Fig. 6) suggests that suitable

549 habitats underwent expansions and contractions during the glacial periods.

550 In addition to the inferences of past population dynamics, predictions about the ability of species

551 to respond to future climate change play an important role in alerting potential risks to

552 biodiversity. In fact, many studies have investigated the response of biodiversity to climate

553 change, and most of them indicate that current and future rates of these changes may be too fast

554 for the ecological niche to evolve (Fraser et al., 2012; Rolland et al., 2018). This is particularly

555 critical in species with low dispersal capacity such as amphibians, which makes them potentially

556 less able to respond to changes induced by climate and, consequently, more vulnerable to 
557 extinction (Duan et al., 2016). In this context, the genetic impoverishment at northern area of the

558 distributional range of $B$. leptopus is of great concern, given a climate change scenario based on

559 increases in temperatures and aridity in central-southern Chile.

560

\section{Conclusions}

562 Our study on genetic diversity throughout the geographic range of B. leptopus, supporting the 563 existence of four lineages distributed along $\sim 1000 \mathrm{~km}$ of length in southwestern Patagonia,

564 including glaciated and no glaciated areas by the LGM. The two northernmost lineages are

565 present in a region with poorly preserved forest patches, whilst the southern lineages are

566 geographically more heterogeneous, suggesting that extensive forests would have allowed

567 dispersion among breeding groups over time scales. Late Pleistocene divergence estimates for

568 the first diversification of the B. leptopus, that separate the North and South clades, also

569 supported by the SDM for the LIG, are consistent with a Pleistocene isolation followed by 570 interglacial dispersion. The $\mathrm{ABC}$ analyses also supported the hypothesis of two putative refugia

571 at different times during the Pleistocene, concordant with a patchy distribution of the species

572 during the Middle Holocene. In addition, northern populations of B. leptopus showed the highest

573 degree of isolation, deserving special attention since considering an increase of the temperatures

574 and aridity in the center-south of Chile, and that they do not have connectivity with nearby

575 populations, they could end up disappearing.

576

577 Acknowledgements 
578 The authors are grateful to Pablo Orozco Ter Wengel for revision and valuable comments on an

579 early draft of manuscript. We also thank three anonymous referees that significantly improved

580 our work. We are grateful to Nicolás I. González for field assistance.

581

582 References

583 Andersson L. 1996. An ontological dilemma: epistemology and methodology of historical 584 biogeography. Journal of Biogeography 23:269-277. DOI:10.1046/j.1365-

585 2699.1996.00091.x.

586 Arroyo-Santos A, Olson ME, Vergara-Silva F. 2014. The phylogeography debate and the epistemology of model-based evolutionary biology. Biology \& Philosophy 29:833-850.

588 DOI:10.1007/s10539-013-9391-1.

Beaumont MA, Zhang W, Balding DJ. 2002. Approximate Bayesian computation in population genetics. Genetics 162:2025-2035.

591 Beebee T. 1996. Ecology and Conservation of Amphibians. Netherlands: Springer.

592 Beerli P. 2006. Comparison of Bayesian and maximum-likelihood inference of population genetic parameters. Bioinformatics 22:341-345. DOI:10.1093/bioinformatics/bti803.

594 Breitman MF, Avila LJ, Sites JW, Morando M. 2011. Lizards from the end of the world: phylogenetic relationships of the Liolaemus lineomaculatus section (Squamata: Iguania: Liolaemini). Molecular Phylogenetics and Evolution 59:364-376. DOI:10.1016/j.ympev.2011.02.008.

598 Broquet T, Berset-Braendli L, Emaresi G, Fumagalli L. 2007. Buccal swabs allow efficient and 599 reliable microsatellite genotyping in amphibians. Conservation Genetics 8:509-511. DOI:10.1007/s10592-006-9180-3. 
601 Busse K. 1971. Desarrollo de Batrachyla leptopus Bell con observaciones sobre su ecología y 602 comportamiento (Amphibia; Leptodactylidae). Investigaciones Zoológicas Chilenas $603 \quad 15: 5-63$.

604 Carnaval AC, Waltari E, Rodrigues MT, Rosauer D, VanDerWal J, Damasceno R, Prates I, 605 606 607 608 Strangas M, Spanos Z, Rivera D, Pie MR, Firkowski CR, Bornschein MR, Ribeiro LF \&

Carstens BC, Dewey TA. 2010. Species delimitation using a combined coalescent and information theoretic approach: An example from Nort American Myotis bats. Systematic Biology 59:400-414.

612 Clark PU, Dyke AS, Shakun JD, Carlson AE, Clark J, Wohlfarth B, Mitrovica JX, Hostetler SW, 613 McCabe AM. 2009. The last glacial maximum. Science 325:710-714. DOI:10.1126/science.1172873.

615 Cornuet JM, Pudlo P, Veyssier J, Dehne-Garcia A, Gautier M, Leblois R, Marin JM, Estoup A. 616 2014. DIYABC v2.0: a software to make approximate Bayesian computation inferences about population history using single nucleotide polymorphism, DNA sequence and microsatellite data. Bioinformatics 30:1187-1189. DOI:10.1093/bioinformatics/btt763.

Coronato A, Martínez O, Rabassa J. 2004. Glaciations in Argentine Patagonia, southern South America. Developments in Quaternary Sciences 2:49-67. DOI:10.1016/S15710866(04)80111-8.

622 Cosacov A, Sérsic AN, Sosa V, Johnson LA, Cocucci AA. 2010. Multiple periglacial refugia in 623 the Patagonian steppe and post-glacial colonization of the Andes: the phylogeography of 

2699.2010.02307.x.

626 Crisp MD, Trewick SA, Cook LG. 2011. Hypothesis testing in biogeography. Trends in Ecology \& Evolution 26:66-72. DOI:10.1016/j.tree.2010.11.005.

Csilléry K, Blum MGB, Gaggiotti OE, François O. 2010. Approximate Bayesian computation (ABC) in practice. Trends in Ecology \& Evolution 25:410-418. DOI:10.1016/j.tree.2010.04.001.

Cuevas CC, Cifuentes SL. 2010. Amphibia, Anura, Ceratophryidae, Batrachyla leptopus Bell, 1843: new records updating and geographic distribution map, Chile. Check List 6:633636. DOI:10.15560/6.4.633.

Degnan SM, Moritz C. 1992. Phylogeography of mitochondrial DNA in two species of whiteeyes in Australia. The Auk 109:800-811. DOI:10.2307/4088154.

Dolman G, Phillips B. 2004. Single copy nuclear DNA markers characterized for comparative phylogeography in Australian wet tropics rainforest skinks. Molecular Ecology Notes 4:185-187. DOI:10.1111/j.1471-8286.2004.00609.x.

Drummond AJ, Rambaut A. 2007. BEAST: Bayesian evolutionary analysis by sampling trees. BMC Evolutionary Biology 7:214-214. DOI:10.1186/1471-2148-7-214.

Duan RY, Kong XQ, Huang MY, Varela S, Ji X. 2016. The potential effects of climate change on amphibian distribution, range fragmentation and turnover in China. PeerJ 4:e2185. DOI:10.7717/peerj.2185.

645

Excoffier L, Laval G, Schneider S. 2005. ARLEQUIN (version 3.0): an integrated software package for population genetics data analysis. Evolutionary Bioinformatics Online 1:4750. DOI:10.1177/117693430500100003. 
647 Fitzpatrick SW, Brasileiro CA, Haddad CFB, Zamudio KR. 2009. Geographical variation in 648 genetic structure of an Atlantic Coastal Forest frog reveals regional differences in habitat 649 stability. Molecular Ecology 18:2877-2896. DOI:10.1111/j.1365-294X.2009.04245.x.

650 Folmer O, Black M, Hoeh W, Lutz R, Vrijenhoek R. 1994. DNA primers for amplification of 651 mitochondrial cytochrome c oxidase subunit I from diverse metazoan invertebrates.

652 Molecular Marine Biology and Biotechnology 3:294-299.

653 Fontanella FM, Olave M, Avila LJ, Sites JW, Morando M. 2012. Molecular dating and diversification of the South American lizard genus Liolaemus (subgenus Eulaemus) based on nuclear and mitochondrial DNA sequences. Zoological Journal of the Linnean Society 164:825-835. DOI:10.1111/j.1096-3642.2011.00786.x.

Formas JR. 1976. Descriptions of Batrachyla (Amphibia, Anura, Leptodactylidae) tadpoles. Journal of Herpetology 10:221-225.

Formas JR. 1995. Anfibios. In: Simonetti JA, Arroyo MTK, Spotorno AE \& Lozada E, eds. Diversidad Biológica de Chile Comisión Nacional de Investigación Científica y Tecnológica, Santiago, 314-325.

662

663

664

665

666

667

668 669

Formas JR, Brieva LM. 2000. Population genetics of the Chilean frog Batrachyla leptopus (Leptodactylidae). Genetics and Molecular Biology 23:43-48. DOI:10.1590/S141547572000000100007.

Fraser CI, Nikula R, Ruzzante DE, Waters JM. 2012. Poleward bound: biological impacts of Southern Hemisphere glaciation. Trends in Ecology \& Evolution 27:462-471. DOI:10.1016/j.tree.2012.04.011.

Freeland JR. 2020. Molecular Ecology. Hoboken, USA: Wiley John and Sons.

Fu YX, Li WH. 1993. Statistical tests of neutrality of mutations. Genetics 133:693-709. 
670 Gallardo MH, Suárez-Villota EY, Nuñez JJ, Vargas RA, Haro R, Köhler N. 2013. Phylogenetic

671

672

673

674

675

676

677

678

679

680

681

682

683

684

685

686

687

688

689

690

691

692 analysis and phylogeography of the tetraploid rodent Tympanoctomys barrerae

(Octodontidae): Insights on its origin and the impact of Quaternary climate changes on population dynamics. Biological Journal of the Linnean Society of London 108:453-469.

DOI:10.1111/j.1095-8312.2012.02016.x.

Gamble T, Berendzen PB, Shaffer HB, Starkey DE, Simons AM. 2008. Species limits and phylogeography of North American cricket frogs (Acris: Hylidae). Molecular Phylogenetics and Evolution 48:112-125. DOI:10.1016/j.ympev.2008.03.015.

Gavin D, Heath KD, McGlone M, Gavin DG, Gavin DG, Fitzpatrick MC, Gugger PF, Heath KD. 2014. Climate refugia: joint inference from fossil records, species distribution models and phylogeography. New Phytologist 204:37-54. DOI:10.1111/nph.12929.

Giarla TC, Jansa SA. 2015. The impact of Quaternary climate oscillations on divergence times and historical population sizes in Thylamys opossums from the Andes. Molecular Ecology 24:2495-2506. DOI:10.1111/mec.13173.

Goebel AM, Donnelly JM, Atz ME. 1999. PCR primers and amplification methods for 12S ribosomal DNA, the control region, cytochrome oxidase $\mathrm{I}$, and cytochrome $\mathrm{b}$ in bufonids and other frogs, and an overview of PCR primers which have amplified DNA in amphibians successfully. Molecular Phylogenetics and Evolution 11:163-199. DOI:10.1006/mpev.1998.0538.

González-Ittig RE, Rossi-Fraire HJ, Cantoni GE, Herrero ER, Benedetti R, Gallardo MH, Gardenal CN. 2010. Population genetic structure of long-tailed pygmy rice rats (Oligoryzomys longicaudatus) from Argentina and Chile based on the mitochondrial control region. Canadian Journal of Zoology 88:23-35. DOI:10.1139/Z09-115. 
693 Grant WS. 2015. Problems and cautions with sequence mismatch analysis and Bayesian skyline 694 plots to infer historical demography. Journal of Heredity 106: 333-346.

695 DOI:10.1093/jhered/esv020.

696 Guillot G, Mortier F, Estoup A. 2005. GENELAND: a computer package for landscape genetics. 697 Molecular Ecology Notes 5:712-715. DOI:10.1111/j.1471-8286.2005.01031.x.

698 Heled J, Drummond AJ. 2008. Bayesian inference of population size history from multiple loci. BMC Evolutionary Biology 8:289-289. DOI:10.1186/1471-2148-8-289.

Heled J, Drummond AJ. 2010. Bayesian inference of species trees from multilocus data.

701 Molecular Biology and Evolution 27:570-580. DOI:10.1093/molbev/msp274.

702

703

Heusser CJ, Flint RF. 1977. Quaternary glaciations and environments of northern Isla Chiloé,

704 Hewitt GM. 2000. The genetic legacy of the ice ages. Nature 405:907-913. Chile. Geology 5:305-308. DOI:10.1130/0091-7613(1977)5<305:QGAEON>2.0.CO;2. DOI:10.1038/35016000.

706

707

708

709

710

711

712

713

714

715

Hewitt GM. 2004. Genetic consequences of climatic oscillations in the Quaternary. Philosophical Transactions of the Royal Society of London B Biological Sciences 359:183-195. DOI:10.1098/rstb.2003.1388.

Hijmans RJ, Cameron SE, Parra JL, Jones PG, Jarvis A. 2005. Very high resolution interpolated climate surfaces for global land areas. International Journal of Climatology 25:19651978. DOI:10.1002/joc.1276.

Himes CMT, Gallardo MH, Kenagy GJ. 2008. Historical biogeography and post-glacial recolonization of South American temperate rain forest by the relictual marsupial Dromiciops gliroides. Journal of Biogeography 35:1415-1424. DOI:10.1111/j.13652699.2008.01895.x. 
716 Ho SYW, Shapiro B. 2011. Skyline-plot methods for estimating demographic history from 717 nucleotide sequences. Molecular Ecology Resources 11:423-434. DOI:10.1111/j.1755-

718 0998.2011.02988.x.

719 Holsinger KE, Weir BS. 2009. Genetics in geographically structured populations: defining, estimating and interpreting FST. Nature Reviews Genetics 10:639-650. DOI:10.1038/nrg2611.

722

723

724

725

726

727

728

729

730

731

732

733

734

735

736

737

Huelsenbeck JP, Rannala B. 2004. Frequentist properties of Bayesian posterior probabilities of phylogenetic trees under simple and complex substitution models. Systematic Biology 53:904-913. DOI:10.1080/10635150490522629.

Hung C-M, Drovetski SV, Zink RM. 2016. Matching loci surveyed to questions asked in phylogeography. Proceedings of the Royal Society of London. B 283: 20152340. DOI:10.1098/rspb.2015.2340

Huson DH, Bryant D. 2006. Application of phylogenetic networks in evolutionary studies. Molecular Biology and Evolution 23:254-267. DOI:10.1093/molbev/msj030.

Inoue K, Monroe EM, Elderkin CL, Berg DJ. 2014. Phylogeographic and population genetic analyses reveal Pleistocene isolation followed by high gene flow in a wide ranging, but endangered, freshwater mussel. Heredity 112:282-290. DOI:10.1038/hdy.2013.104.

Irisarri I, Mauro DS, Abascal F, Ohler A, Vences M, Zardoya R. 2012. The origin of modern frogs (Neobatrachia) was accompanied by acceleration in mitochondrial and nuclear substitution rates. BMC Genomics 13:626-626. DOI:10.1186/1471-2164-13-626.

Keppel G, Van Niel KP, Wardell-Johnson GW, Yates CJ, Byrne M, Mucina L, Schut AGT, Hopper SD, Franklin SE. 2012. Refugia: Identifying and understanding safe havens for 
biodiversity under climate change. Global Ecology and Biogeography 21:393-404. DOI:10.1111/j.1466-8238.2011.00686.x.

740 Lanfear R, Frandsen PB, Wright AM, Senfeld T, Calcott B. 2017. Partitionfinder 2: new methods for selecting partitioned models of evolution for molecular and morphological phylogenetic analyses. Molecular Biology and Evolution 34:772-773. DOI:10.1093/molbev/msw260.

Le Roux JP. 2012. A review of Tertiary climate changes in southern South America and the Antarctic Peninsula. Part 2: continental conditions. Sedimentary Geology 247-248:21-38. DOI:10.1016/j.sedgeo.2011.12.001.

Lessa EP, D'Elía G, Pardiñas UFJ. 2010. Genetic footprints of late Quaternary climate change in the diversity of Patagonian-Fueguian rodents. Molecular Ecology 19:3031-3037. DOI:10.1111/j.1365-294X.2010.04734.x.

Li N, Stephens M. 2003. Modeling linkage disequilibrium and identifying recombination hotspots using single-nucleotide polymorphism data. Genetics 165:2213-2233.

752 753
Li WLS, Drummond AJ. 2012. Model averaging and Bayes factor calculation of relaxed molecular clocks in Bayesian phylogenetics. Molecular Biology and Evolution 29:751761. DOI:10.1093/molbev/msr232.

Librado P, Rozas J. 2009. DnaSP v5: a software for comprehensive analysis of DNA polymorphism data. Bioinformatics 25:1451-1452. DOI:10.1093/bioinformatics/btp187.

Martin AP, Palumbi SR. 1993. Body size, metabolic rate, generation time, and the molecular clock. Proceedings of the National Academy of Sciences of the United States of America 90:4087-4091. DOI:10.1073/pnas.90.9.4087. 
760 Mercer JH. 1972. Chilean glacial chronology 20,000 to 11,000 carbon 14 years ago: some global $761 \quad$ comparisons. Science 176:1118-1120.

762 Nabholz B, Glémin S, Galtier N. 2009. The erratic mitochondrial clock: variations of mutation

763

764

765

766

767

768

769

770

771

772

773

774

775

776

777

778

779

780

781

782 rate, not population size, affect mtDNA diversity across mammals and birds. $B M C$ Evolutionary Biology 9: 54. DOI: 10.1186/1471-2148-9-54.

Nei M. 1987. Molecular Evolutionary Genetics. New York: Columbia University Press.

Nichols RA, Hewitt GM. 1994. The genetic consequences of long-distance dispersal during colonization. Heredity 72:312-317. DOI:10.1038/hdy.1994.41.

Nuñez JJ, Wood NK, Rabanal FE, Fontanella FM, Sites JW, Jr. 2011. Amphibian phylogeography in the Antipodes: Refugia and postglacial colonization explain mitochondrial haplotype distribution in the Patagonian frog Eupsophus calcaratus (Cycloramphidae). Molecular Phylogenetics and Evolution 58:343-352. DOI:10.1016/j.ympev.2010.11.026.

Ortíz-Jaureguizar E, Cladera GA. 2006. Paleoenvironmental evolution of southern South America during the Cenozoic. Journal of Arid Environments 66:498-532. DOI:10.1016/j.jaridenv.2006.01.007.

Otto-Bliesner BL, Brady EC, Fasullo J, Jahn A, Landrum L, Stevenson S, Rosenbloom N, Mai A, Strand G. 2016. Climate variability and change since $850 \mathrm{CE}$ : an ensemble approach with the community earth system model. Bulletin of the American Meteorological Society 97:787-801. DOI:10.1175/BAMS-D-14-00233.1.

Papadopoulou A, Knowles LL. 2016. Toward a paradigm shift in comparative phylogeography driven by trait-based hypotheses. Proceedings of the National Academy of Sciences of the United States of America 113:8018. DOI:10.1073/pnas.1601069113. 
783 Phillips SJ, Anderson RP, Dud M, Schapire RE, Blair ME. 2017. Opening the black box: an

784 open-source release of Maxent. Ecography 40:887-893. DOI:10.1111/ecog.03049.

785 Posada D, Crandall KA. 2001. Intraspecific gene genealogies: trees grafting into networks.

786 Trends in Ecology \& Evolution 16:37-45. DOI:10.1016/S0169-5347(00)02026-7.

787 Premoli AC, Kitzberger T, Veblen TT. 2000. Isozyme variation and recent biogeographical

788 history of the long-lived conifer Fitzroya cupressoides. Journal of Biogeography 27:251-

789 260. DOI:10.1046/j.1365-2699.2000.00402.x.

790 Prohl H, Ron SR, Ryan MJ. 2010. Ecological and genetic divergence between two lineages of

791 Middle American túngara frogs Physalaemus (=Engystomops) pustulosus. BMC

792 Evolutionary Biology 10:146. DOI:10.1186/1471-2148-10-146.

793 Rabassa J. 2011. Late Cenozoic glaciations in Patagonia and Tierra del Fuego: an update review.

794 Developments in Quaternary Sciences 11:151-204. DOI:10.1111/j.1095-

$795 \quad$ 8312.2011.01681.x.

796 Rabassa J, Clapperton CM. 1990. Quaternary glaciations in the southern hemisphere: an

797 overview. Quaternary Science Reviews 9:299-304. DOI:10.1016/0277-3791(90)90024-5.

798 Rambaut A, Suchard MA, Xie D, Drummond AJ. 2014. Tracer v1.6. Available at:

799 http://beast.bio.ed.ac.uk/Tracer.

800 Ramos-Onsins SE, Rozas J. 2002. Statistical properties of new neutrality tests against population $801 \quad$ growth. Molecular Biology and Evolution 19:2092-2100.

802 DOI:10.1093/oxfordjournals.molbev.a004034.

803 Robinson JD, Bunnefeld L, Hearn J, Stone GN, Hickerson MJ. 2014. ABC inference of multi-

804 population divergence with admixture from unphased population genomic data.

805 Molecular Ecology 23:4458-4471. DOI:10.1111/mec.12881. 
806 Rogers AR, Harpending H. 1992. Population growth makes waves in the distribution of pairwise 807 genetic differences. Molecular Biology and Evolution 9:552-569.

808 DOI:10.1534/genetics. 103.024182.

809 Rolland J, Silvestro D, Schluter D, Guisan A, Broennimann O, Salamin N. 2018. The impact of 810 endothermy on the climatic niche evolution and the distribution of vertebrate diversity.

811 Nature Ecology and Evolution 2:459-464. DOI:10.1038/s41559-017-0451-9.

812 Ronquist F, Teslenko M, van der Mark P, Ayres DL, Darling A, Höhna S, Larget B, Liu L, 813 Suchard MA, Huelsenbeck JP. 2012. MrBayes 3.2: Efficient Bayesian Phylogenetic 814 Inference and Model Choice Across a Large Model Space. Systematic Biology 61:539$815 \quad$ 542. DOI:10.1093/sysbio/sys029.

816 Ruzzante DE, Walde SJ, Cussac VE, Dalebout ML, Seibert J, Ortubay S, Habit E. 2006.

817 Phylogeography of the Percichthyidae (Pisces) in Patagonia: roles of orogeny, glaciation, 818 and volcanism. Molecular Ecology 15:2949-2968. DOI:10.1111/j.1365819 294X.2006.03010.x.

820 Ruzzante DE, Walde SJ, Gosse JC, Cussac VE, Habit E, Zemlak TS, Adams EDM. 2008.

821 Climate control on ancestral population dynamics: insight from Patagonian fish $822 \quad$ phylogeography. Molecular Ecology 17:2234-2244. DOI:10.1111/j.1365$823 \quad 294 X .2008 .03738 . x$.

824 Schwarz G. 1978. Estimating the dimension of a model. The Annals of Statistics 6:461-464. DOI:10.1214/aos/1176344136.

826 Segovia RA, Armesto JJ. 2015. The Gondwanan legacy in South American biogeography. 827 Journal of Biogeography 42:209-217. DOI:10.1111/jbi.12459. 
828 Sérsic AN, Cosacov A, Cocucci AA, Johnson LA, Pozner R, Avila LJ, Sites JW, Jr., Morando

829 M. 2011. Emerging phylogeographical patterns of plants and terrestrial vertebrates from

$830 \quad$ Patagonia. Biological Journal of the Linnean Society of London 103:475-494.

$831 \quad$ DOI:10.1111/j.1095-8312.2011.01656.x.

832 Shimodaira H, Hasegawa M. 1999. Multiple comparisons of Log-Likelihoods with applications

833 to phylogenetic inference. Molecular Biology and Evolution 16:1114-1114.

834 DOI:10.1093/oxfordjournals.molbev.a026201.

835 Stephens M, Donnelly P. 2003. A comparison of bayesian methods for haplotype reconstruction

836 from population genotype data. American Journal of Human Genetics 73:1162-1169.

837 DOI:10.1086/379378.

838 Suárez-Villota EY, Quercia CA, Díaz LM, Vera-Sovier V, Nuñez JJ. 2018. Speciation in a biodiversity hotspot: phylogenetic relationships, species delimitation, and divergence times of Patagonian ground frogs from the Eupsophus roseus group (Alsodidae). PloS

842 One 13:e204968. DOI:10.1371/journal.pone.0204968.

844

Sunnåker M, Busetto AG, Numminen E, Corander J, Foll M, Dessimoz C. 2013. Approximate Bayesian computation. PLoS Computational Biology 9:e1002803. DOI:10.1371/journal.pcbi.1002803.

846

Tajima F. 1989. Statistical method for testing the neutral mutation hypothesis by DNA polymorphism. Genetics 123:585-595. DOI:PMC1203831.

847 Tremetsberger K, Urtubey E, Terrab A, Baeza CM, Ortíz MA, Talavera M, Konig C, Temsch

848 EM, Kohl G, Talavera S, Stuessy TF. 2009. Pleistocene refugia and polytopic

849 replacement of diploids by tetraploids in the Patagonian and Subantarctic plant 
Hypochaeris incana (Asteraceae, Cichorieae). Molecular Ecology 18:3668-3682.

851 DOI:10.1111/j.1365-294X.2009.04298.x.

852 Úbeda C, Nuñez JJ. 2006. New parental care behaviours in two telmatobiine genera from 853 temperate Patagonian forests: Batrachyla and Eupsophus (Anura: Leptodactylidae). Amphibia-Reptilia 27:441-444. DOI:10.1163/156853806778190015.

855 Victoriano PF, Ortiz JC, Benavides E, Adams BJ, Sites JW, Jr. 2008. Comparative 856 phylogeography of codistributed species of Chilean Liolaemus (Squamata: Tropiduridae) from the central-southern Andean range. Molecular Ecology 17:2397-2416.

Vidal MA, Ibáñez S, Moreno PI, Poulin E. 2016. Phylogeography of a Patagonian lizard and 860

861 frog: congruent signature of southern glacial refuges. Austral Ecology 41:405-414.

Vidal-Russell R, Souto CP, Premoli AC. 2011. Multiple Pleistocene refugia in the widespread 863 Patagonian tree Embothrium coccineum (Proteaceae). Australian Journal of Botany

864 59:299-314. DOI:10.1071/BT10303.

865 Villagrán C, Hinojosa LF. 1997. Historia de los bosques del sur de Sudamérica, II: análisis 866 fitogeográfico. Revista Chilena de Historia Natural 70:241-267.

867 Waters JM, Fraser CI, Hewitt GM. 2013. Founder takes all: density-dependent processes 868 structure biodiversity. Trends in Ecology \& Evolution 28:78-85.

869 DOI:10.1016/j.tree.2012.08.024.

870

Wiens JJ, Sukumaran J, Pyron RA, Brown RM. 2009. Evolutionary and biogeographic origins of high tropical diversity in old world frogs (Ranidae). Evolution 63:1217-1231. DOI:10.1111/j.1558-5646.2009.00610.x. 
873 Xia X, Xie Z. 2001. DAMBE: software package for data analysis in molecular biology and 874 evolution. Journal of Heredity 92:371-373. DOI:10.1093/jhered/92.4.371.

875 Xia X, Xie Z, Salemi M, Chen L, Wang Y. 2003. An index of substitution saturation and its 876 application. Molecular Phylogenetics and Evolution 26:1-7. DOI:10.1016/S1055$877 \quad 7903(02) 00326-3$.

878 Zemlak TS, Walde SJ, Habit EM, Ruzzante DE. 2011. Climate-induced changes to the ancestral 879 population size of two Patagonian galaxiids: the influence of glacial cycling. Molecular $880 \quad$ Ecology 20:5280-5294. DOI:10.1111/j.1365-294X.2011.05352.x.

881 Zwickl DJ. 2006. Genetic algorithm approaches for the phylogenetic analysis of large biological 882 sequence datasets under the maximum likelihood criterion. Ph.D. dissertation, The 883 University of Texas at Austin.

884

885 
Figure 1

Location map of 19 localities of $B$. leptopus sampled throughout the species' range in Southwestern Patagonia.

The dashed line corresponds to the limits of the LGM. The full names of the populations are provided in Table 1. 


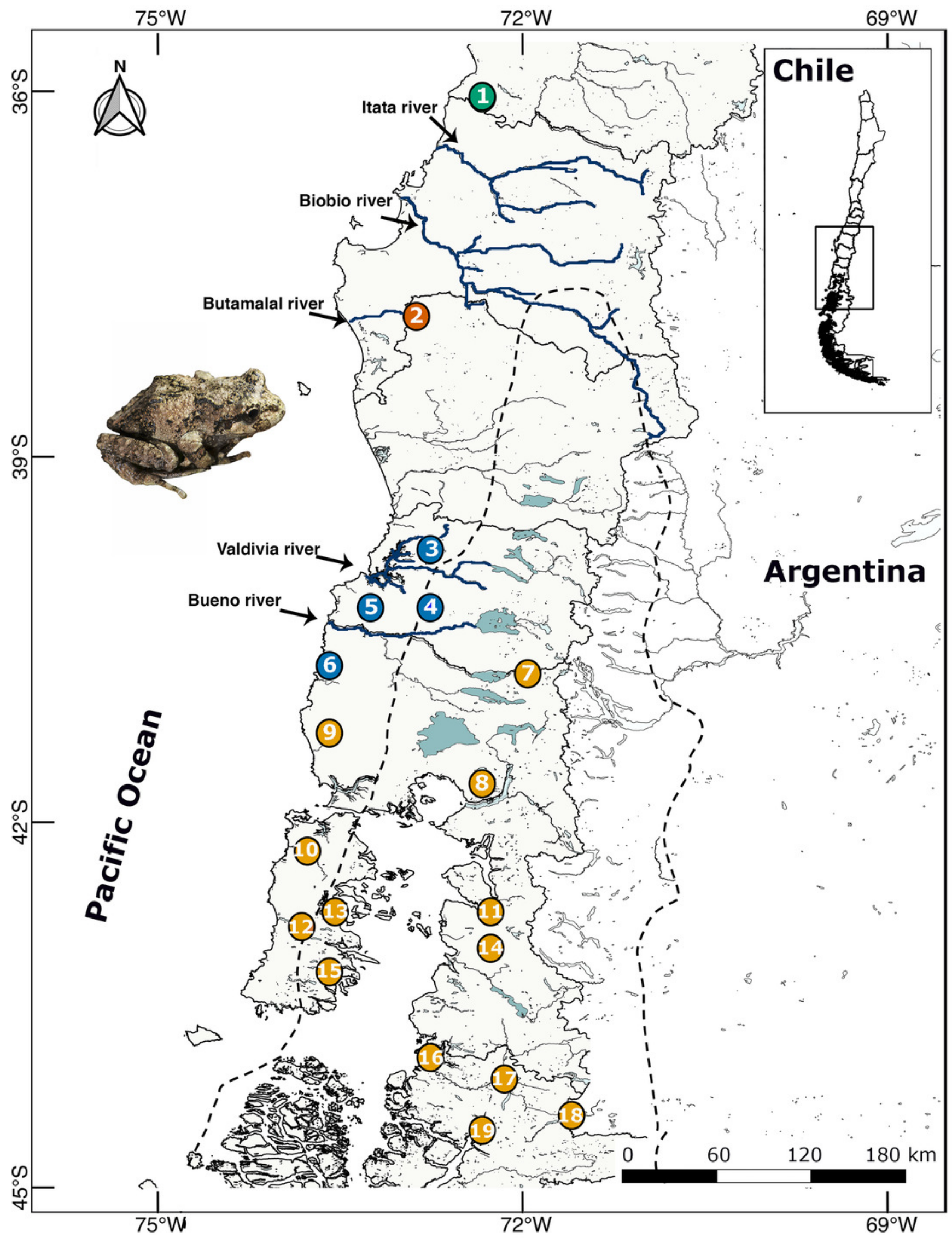




\section{Figure 2}

Genetic structure analyses of Batrachyla leptopus populations.

(A) number of populations simulated from the posterior distribution obtained with GENELAND v4.0; (B) spatial distribution of clusters. Black points correspond to sample sites. Lineage A to $D$ are represented by light grey, orange, light green and dark green, respectively.
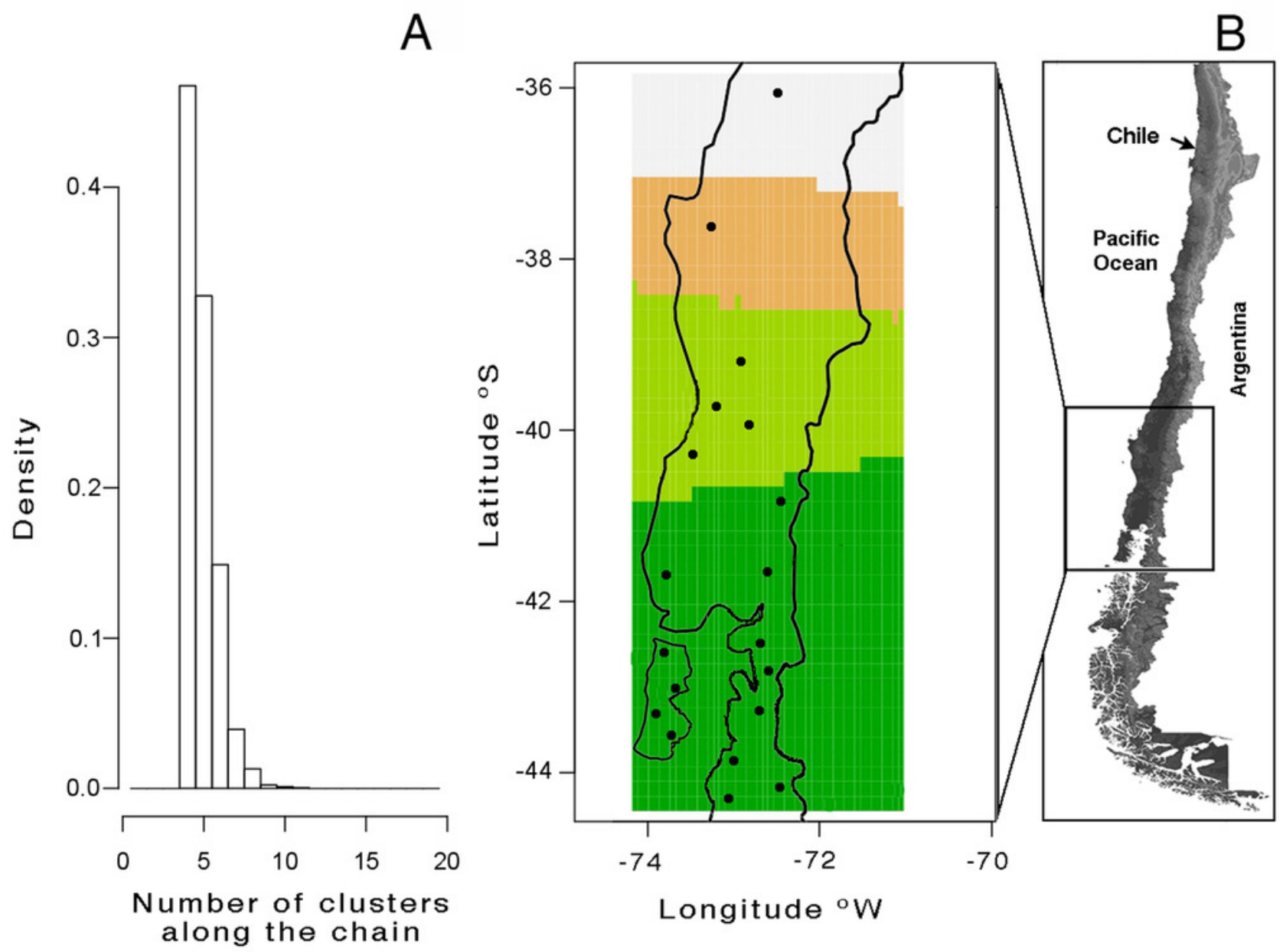
Figure 3

Phylogenetic reconstruction of Batrachyla leptopus.

(A) Bayesian tree of pooled data. Strongly supported lineages are represented with different colours and as lineages A-D. Branch support is based on ML bootstrap resampling and Bayesian posterior probabilities above the branch, and point estimates of selected divergence estimates are below. (B) Genealogical relationship based on unrooted phylogenetic networks showing the north and south clades.

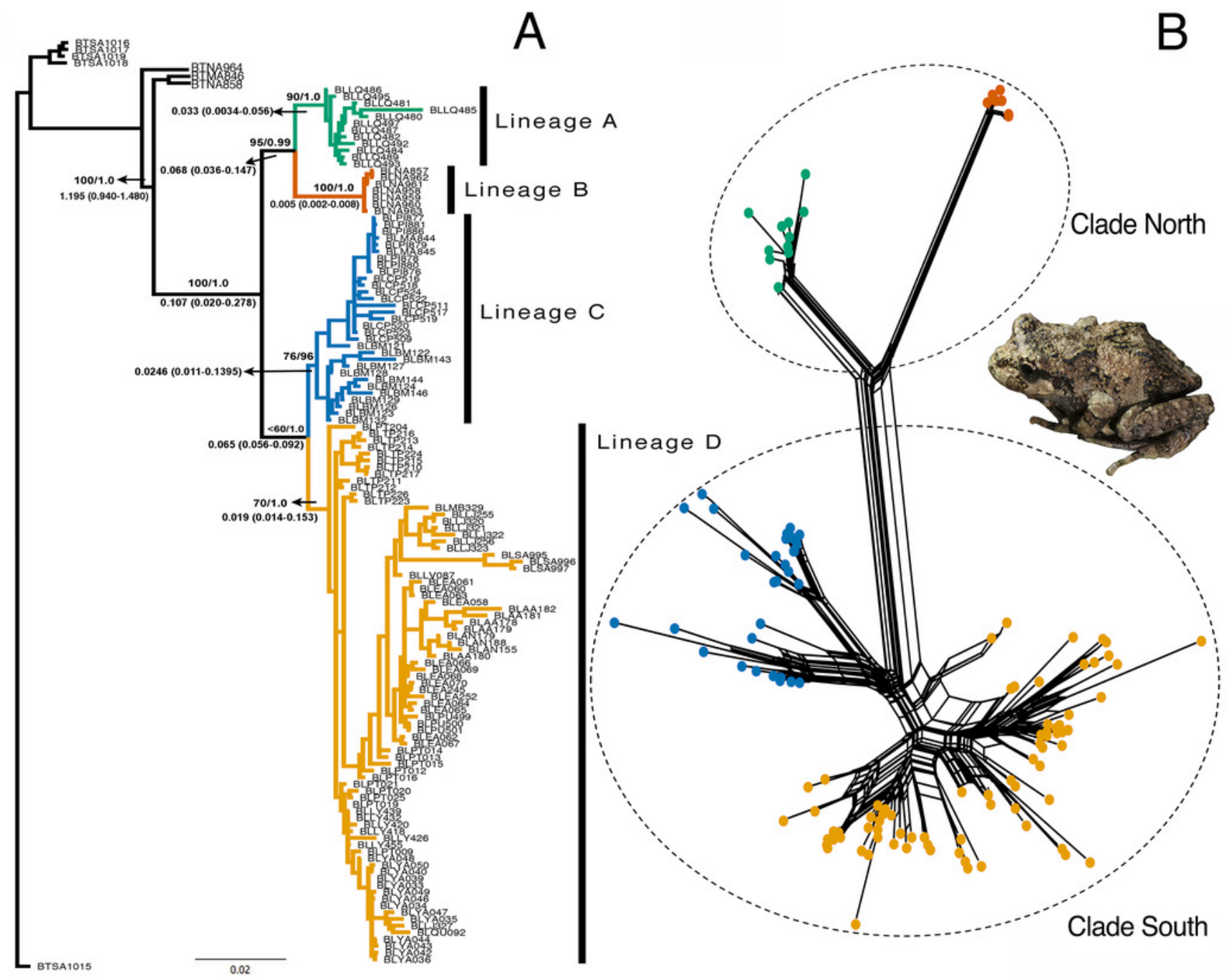




\section{Figure 4}

Historical demographic analysis for each lineage of Batrachyla leptopus.

(left) Mismatch distribution of observed frequencies of pairwise differences among $B$.

leptopus lineages for concatenated data. (right) Extended Bayesian skyline plots analysis.

(A, E) Lineage A. (B, F) Lineage B. (C, G) Lineage C. (D, H) Lineage D. X-axe corresponds to time $(\mathrm{Ma})$ and $\mathrm{y}$-axe corresponds to $\mathrm{Ne}$, the product of effective population size and generation length in years. 

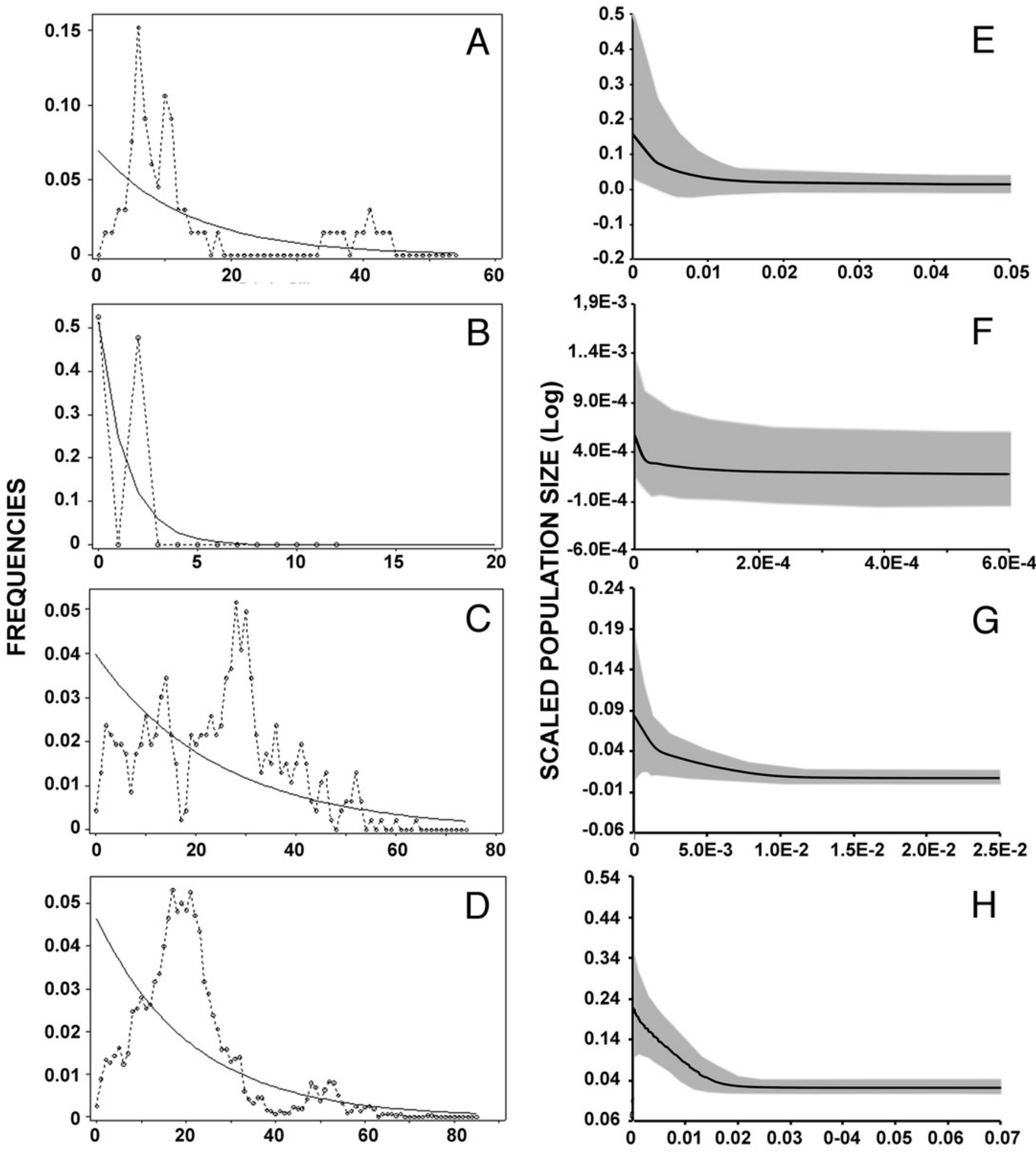

PAIRWISE DIFFERENCES

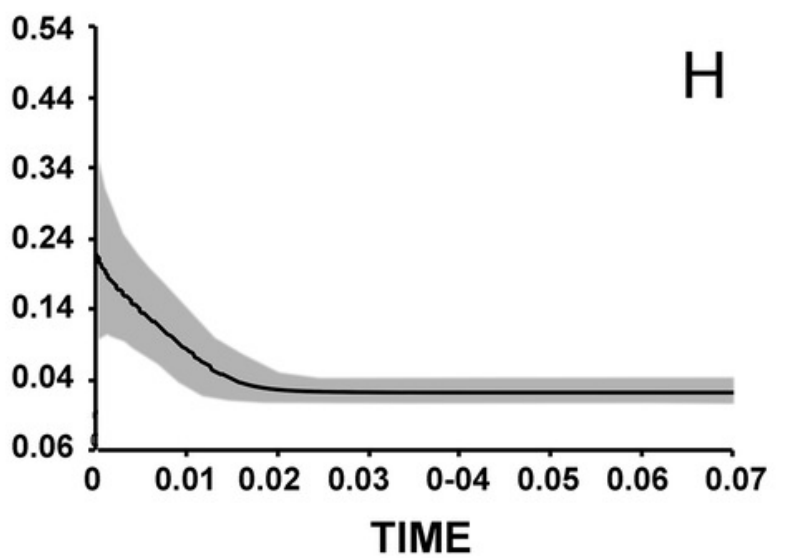


Figure 5

Highest probable ancestral connectivity observed using Approximate Bayesian Computation analysis among the four lineages of $B$. leptopus.

(A) Scenario 1: as a null model all lineages coalesced at t1 in a single refuge. (B) Scenario 2: all lineage coalesced at $\mathrm{t} 2 \mathrm{in}$ a single refuge. (C) Scenario 3: starting at 0 , lineage $A$ coalesced at $t 1$ in a single refuge with the lineage $B$. AB lineage ancestor coalesced at $t 2$ with lineage $C$ and $D$. (D) Scenario 4: lineage $C$ and $D$ coalesced at $t 1$. CD lineage ancestor coalesced at t 2 with lineage $A$ and $B$ in a single refuge. (E) Scenario 5 : starting at 0 , lineage A coalesced at $t 1$ in a single refuge with the lineage $B$, same situation with lineages $C$ and $D$. In the same way, $A B$ and $C D$ lineage ancestors coalesced at $t 2$ in a single refuge.
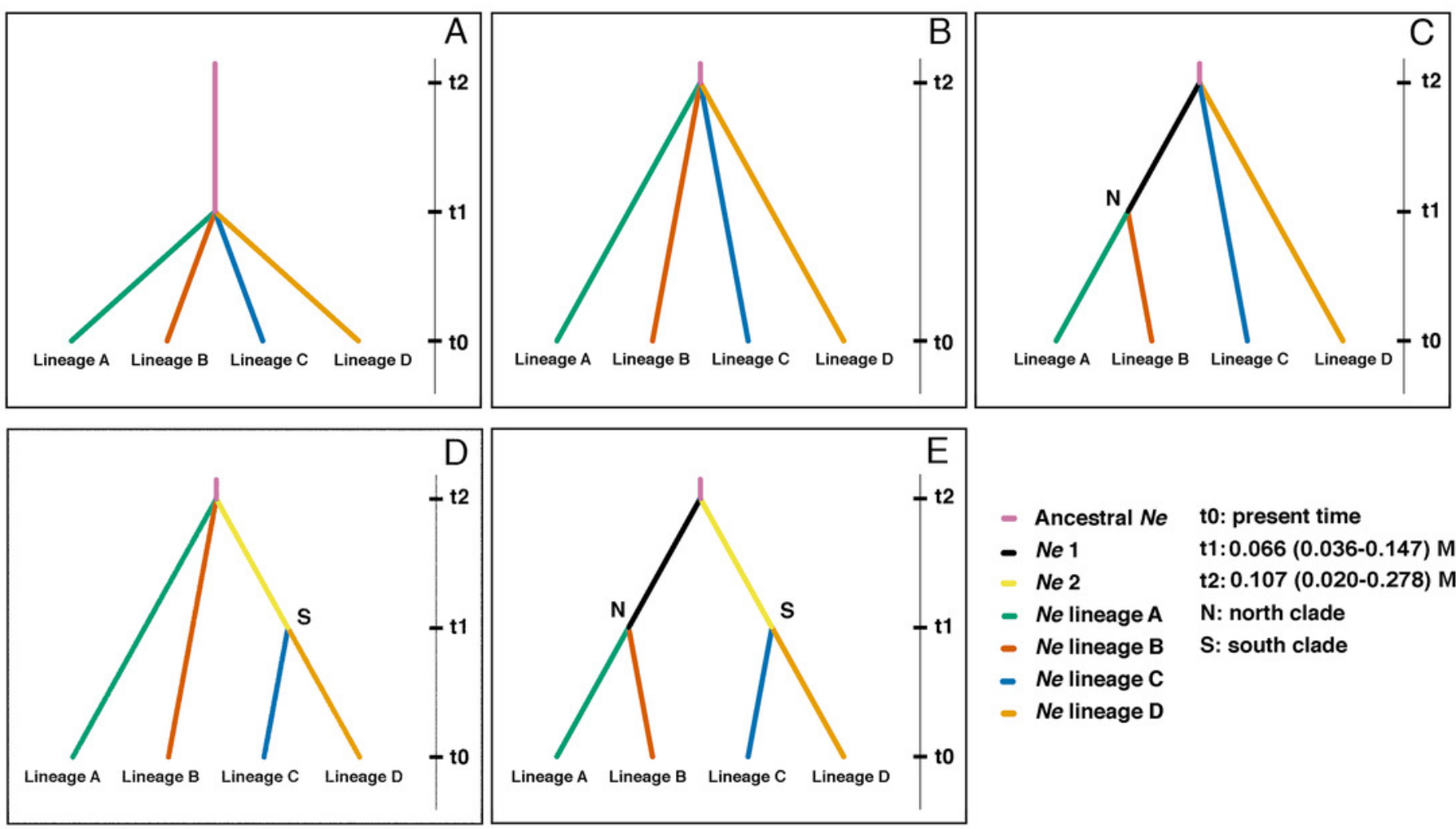

- Ancestral $\mathrm{Ne}$

- Ne 1

- Ne 2

- Ne lineage $A$

- Ne lineage B

- Ne lineage C

- Ne lineage D t0: present time t1: $0.066(0.036-0.147) \mathrm{Ma}$ t2: $0.107(0.020-0.278) \mathrm{Ma}$

$\mathrm{N}$ : north clade

S: south clade 


\section{Figure 6}

Geographical distribution for climatically predicted areas for the occurrence of $B$. leptopus based on current and past bioclimatic variables.

Potential distribution under: (A) current conditions (1960-1990). (B) Mid Holocene (Mid-Hol, $\sim 6,000$ yrs BP). (C) Last Glacial Maximum (LGM 22,000 yrs BP). (D) Last Interglacial Period (LIG, $\sim 130,000$ years before present). Red, orange, and purple represent areas with high probability of $B$. leptopus for each period.
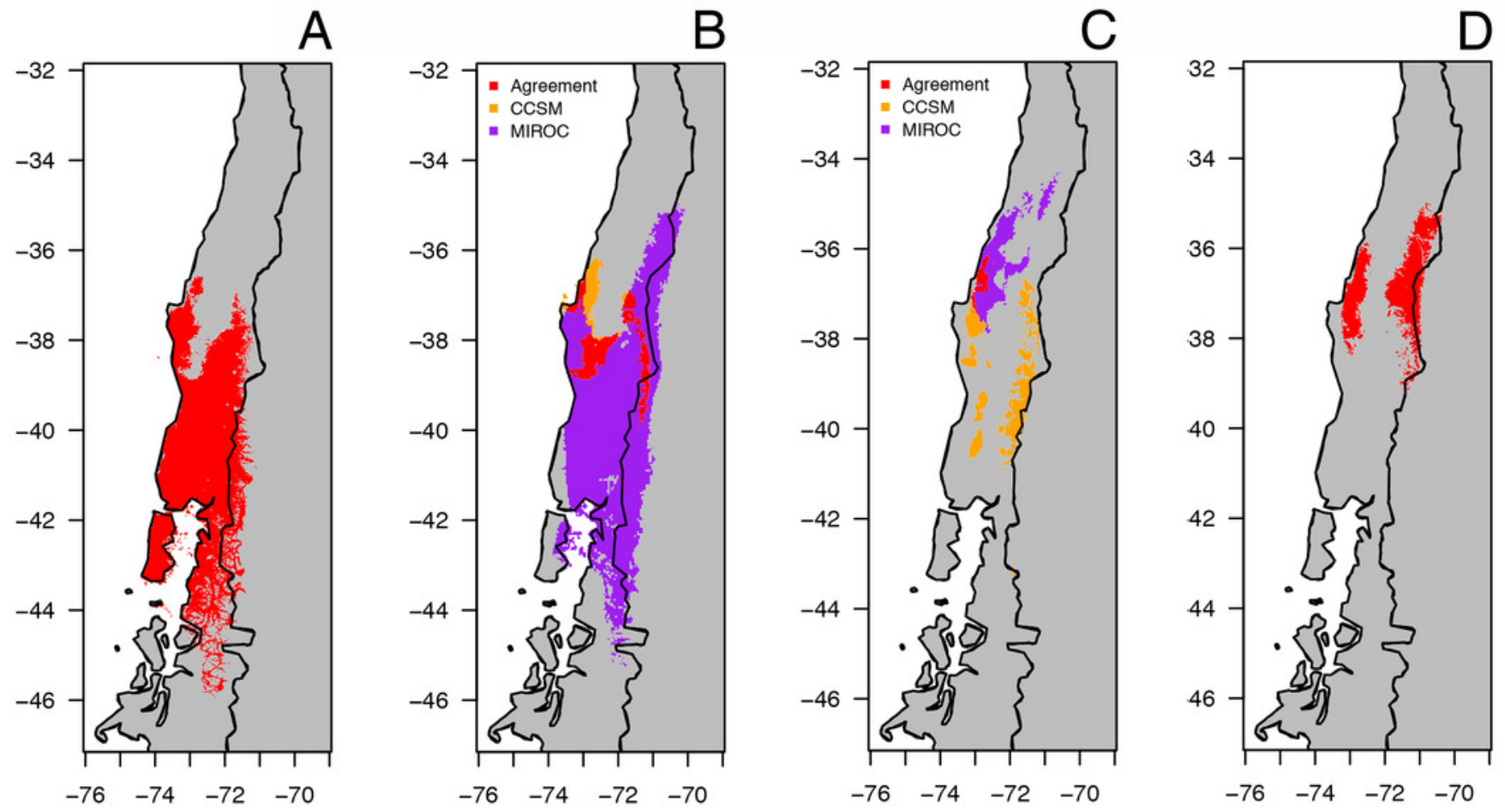


\section{Table 1 (on next page)}

Sampling locations of $B$. leptopus, its coordinates, sample size for each location (N), and lineage structure according to GENELAND. 
1 Table 1: Sampling locations of Batrachyla leptopus with its coordinates, sample size for each location (N), and lineage structure according to GENELAND.

\begin{tabular}{|c|c|c|c|c|c|}
\hline & Location & Latitude & Longitude & $\mathbf{N}$ & $\begin{array}{l}\text { Lineage } \\
\text { structure }\end{array}$ \\
\hline 1 & Los Queules (LQ) & -35.99277778 & -72.52583333 & 12 & $\mathrm{~A}$ \\
\hline 2 & Nahuelbuta (NA) & -37.78861111 & -72.99222222 & 7 & $\mathrm{~B}$ \\
\hline 3 & Mafil (MA) & -39.66964722 & -72.92111111 & 2 & $\mathrm{C}$ \\
\hline 4 & Pichirropulli (PI) & -40.13305556 & -72.90888889 & 7 & \\
\hline 5 & Cordillera Pelada (CP) & -40.14027778 & -73.41777778 & 10 & \\
\hline 6 & Bahía Mansa (BM) & -40.56305556 & -73.73166667 & 12 & \\
\hline 7 & Antillanca (AN) & -40.66888889 & -72.16027778 & 3 & $\mathrm{D}$ \\
\hline 8 & Alerce Andino (AA) & -41.58027778 & -72.54083333 & 5 & \\
\hline
\end{tabular}




\begin{tabular}{|c|c|c|c|}
\hline 9 & Sarao (SA) & -41.16416667 & -73.72722222 \\
\hline 10 & Puntra (PT) & -42.10388889 & -73.87000000 \\
\hline 11 & Pumalín (PU) & -42.61638889 & -72.47805556 \\
\hline 12 & Tepuhueico (TP) & -42.71833333 & -73.94138889 \\
\hline 13 & Isla Lemuy (LY) & -42.62416667 & -73.63722222 \\
\hline 14 & El Amarillo (EA) & -42.89444444 & -72.46833333 \\
\hline 15 & Yaldad (YA) & -43.10527778 & -73.69555556 \\
\hline 16 & Marín Balmaceda (MB) & -43.78388889 & -72.96388889 \\
\hline 17 & La Junta (LJ) & -43.93944444 & -72.36361111 \\
\hline 18 & Lago Verde (LV) & -44.23472222 & -71.84083333 \\
\hline 19 & Queulat (QU) & -44.37694444 & -72.54138889 \\
\hline
\end{tabular}




\section{Table 2 (on next page)}

Genetic diversity by lineage on $B$. leptopus.

N: Sample Size, H: Haplotype number, S: Segregating sites, Hd: Haplotype diversity, Pi:

Nucleotide diversity, Neutrality test indexes (Rozas' $r^{2}$, Tajima's D and Fu's FS). 
2 Table 2: Genetic diversity by lineage. N: Sample Size, H: Haplotype number, S: Segregating sites, Hd: Haplotype diversity, Pi:

3 Nucleotide diversity, Neutrality test indexes (Rozas' r², Tajima's D and Fu's FS).

4

\begin{tabular}{ccccccccc}
\hline Lineage & $\mathbf{N}$ & $\mathbf{H}$ & $\mathbf{S}$ & $\mathbf{H d}$ & $\mathbf{P i}$ & $\mathbf{r}^{2}$ & $\mathbf{D}$ & Fu`s FS \\
\hline $\mathbf{A}$ & 12 & 12 & 58 & 1 & 0.00485 & $0.1501^{* *}$ & $-1.50321^{*}$ & $-1.81336^{*}$ \\
$\mathbf{B}$ & 7 & 2 & 2 & 0.476 & 0.00035 & $0.2381^{* *}$ & $0.68731^{*}$ & $1.14506^{*}$ \\
$\mathbf{C}$ & 31 & 29 & 127 & 0.996 & 0.00891 & $0.0823^{*}$ & $-1.05159^{*}$ & $-1.77929^{*}$ \\
D & 80 & 72 & 150 & 0.998 & 0.00999 & $0.0651^{*}$ & $-1.26706^{*}$ & $-1.34060^{*}$ \\
Total & 130 & 113 & 264 & 0.996 & 0.01448 & $0.0541^{*}$ & $-1.48283^{*}$ & $-2.26131^{*}$
\end{tabular}

5

$* * P<0.02, *$ non significant, $\mathrm{P}<0.10$

6 


\section{Table 3 (on next page)}

Results of hierarchical analysis of molecular variance for Batrachyla leptopus lineages, over nuclear and mitochondrial markers.

Results of hierarchical analysis of molecular variance for Batrachyla leptopus lineages, over mitochondrial, pomc, and crybA1 markers, respectively. $\mathrm{df}=$ degrees of freedom, $\mathrm{SS}=$ sum of squares, $p$-value is based on 1000 permutations. 
1

2 Table 3: Results of hierarchical analysis of molecular variance for Batrachyla leptopus lineages, 3 over mitochondrial, pomc, and crybA1 markers, respectively. $\mathrm{df}=$ degrees of freedom, $\mathrm{SS}=$ sum 4 of squares, $p$-value is based on 1000 permutations.

6

\begin{tabular}{|c|c|c|c|c|c|}
\hline $\begin{array}{l}\text { Source of } \\
\text { variation }\end{array}$ & df & SS & $\begin{array}{c}\text { Variance } \\
\text { components }\end{array}$ & $\begin{array}{l}\text { Percentage } \\
\text { of variation }\end{array}$ & $p$ \\
\hline \multicolumn{6}{|l|}{ Mitochondrial } \\
\hline Among lineages & 3 & 1781.206 & 16.16587 & 35.64715 & 0.034 \\
\hline $\begin{array}{l}\text { Among localities } \\
\text { within lineages }\end{array}$ & 15 & 2036.172 & 20.83160 & 45.93547 & $<0.001$ \\
\hline Within localities & 111 & 926.981 & 8.35222 & 18.41738 & $<0.001$ \\
\hline \multicolumn{6}{|l|}{ pomc } \\
\hline Among lineages & 3 & 32.023 & 0 & 0.00000 & $<0.001$ \\
\hline $\begin{array}{l}\text { Among localities } \\
\text { within lineages }\end{array}$ & 15 & 148.948 & 1.38080 & 51.12677 & $<0.001$ \\
\hline Within localities & 111 & 164.776 & 1.48447 & 54.96532 & 0.293 \\
\hline \multicolumn{6}{|l|}{$\operatorname{cryb} A 1$} \\
\hline Among lineages & 3 & 0.738 & 0.00488 & 4.49187 & 0.212 \\
\hline $\begin{array}{l}\text { Among localities } \\
\text { within lineages }\end{array}$ & 15 & 1.785 & 0.00298 & 2.74255 & 0.153 \\
\hline Within localities & 111 & 11.185 & 0.10076 & 92.76558 & 0.193 \\
\hline
\end{tabular}


Table 4 (on next page)

Type I and Type II error rates and posterior probabilities for each scenario calculated from DIYABC. 
1 Table 4: Type I and Type II error rates and posterior probabilities for each scenario calculated from DIYABC.

2

\begin{tabular}{|c|c|c|c|c|c|c|c|}
\hline True scenario used for & & & ype 2 error $r$ & & & Type 1 error & Posterior probability \\
\hline simulation & Scenario 1 & Scenario 2 & Scenario 3 & Scenario 4 & Scenario 5 & rate & (95\% credible interval) \\
\hline Scenario 1 & - & 0.030 & 0.090 & 0.066 & 0.041 & 0.227 & $0.0438(0.0000-0.4411)$ \\
\hline Scenario 2 & 0.030 & - & 0.053 & 0.057 & 0.057 & 0.197 & $0.0044(0.0000-0.4273)$ \\
\hline Scenario 3 & 0.022 & 0.074 & - & 0.014 & 0.145 & 0.255 & $0.0000(0.0000-0.4076)$ \\
\hline Scenario 4 & 0.020 & 0.094 & 0.003 & - & 0.023 & 0.140 & $0.9339(0.9057-0.9622)$ \\
\hline Scenario 5 & 0.015 & 0.009 & 0.029 & 0.196 & - & 0.250 & $0.0178(0.0000-0.4195)$ \\
\hline
\end{tabular}

